ANL-AFCI-208

\title{
A Validation Study of Existing Neutronics Tools against ZPPR-21 and ZPPR-15 Critical Experiments
}

\author{
W. S. Yang and S. J. Kim \\ Nuclear Engineering Division \\ 9700 South Cass Avenue \\ Argonne National Laboratory \\ Argonne, IL 60439
}

September 30, 2007 
Intentional blank 


\section{Table of Contents}

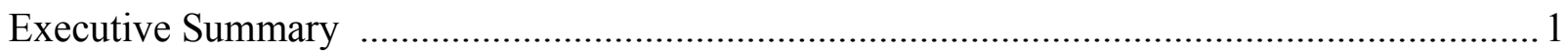

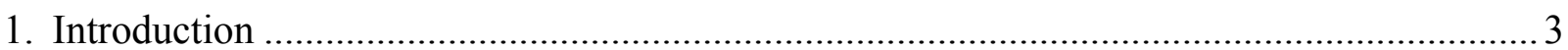

2. Analysis of ZPPR-21 Critical Experiment Benchmarks ................................................... 5

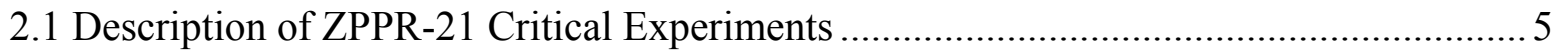

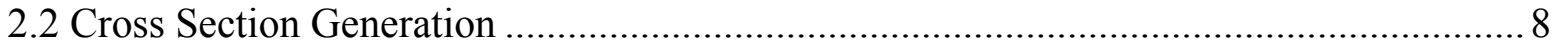

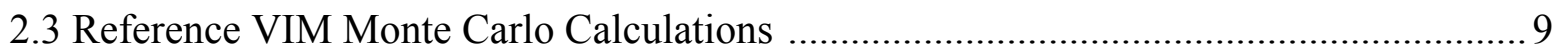

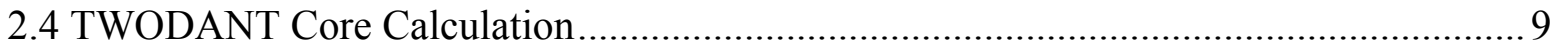

2.4.1 Effect of Scattering Order and Angular Quadrature .............................................. 9

2.4.2 Effect of Anisotropic Scattering Cross Section Correction ........................................ 10

2.4.3 Transport Effect ................................................................................................... 11

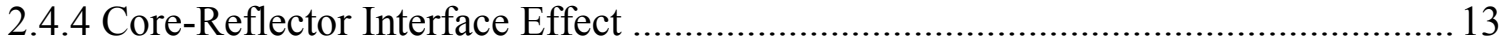

2.5 Verification of $\mathrm{MC}^{2}$-2/TWODANT against VIM Monte Carlo Calculation ................... 15

2.6 Validation of $\mathrm{MC}^{2}$-2/TWODANT against Benchmark Experimental Values ................ 19

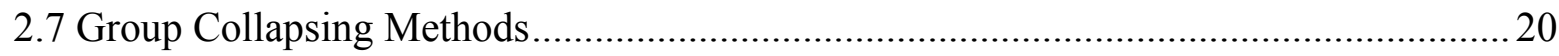

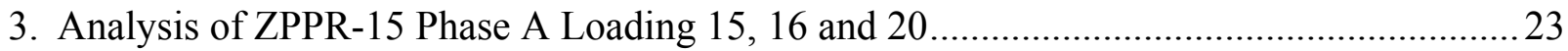

3.1 Description of ZPPR-15 Phase A Critical Experiments ..................................................23

3.1.1 Core Layout of Reference Critical Loading ........................................................23

3.1.2 Plate Geometry Description of Reference Critical Loading .....................................2.25

3.2 Monte Carlo Analysis of ZPPR-15 Reference Critical Loading 15 ……........................2. 28

3.3 Deterministic Model for Core Plate Heterogeneity Effects.................................................. 31

3.4 Deterministic Model for Blanket Plate Heterogeneity Effects ............................................33

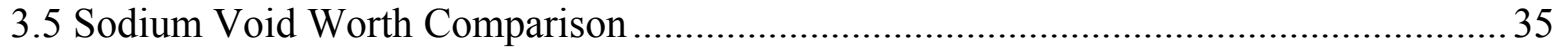

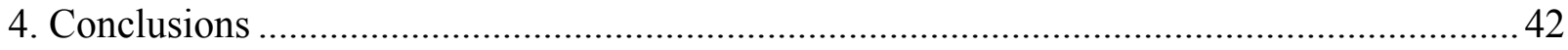

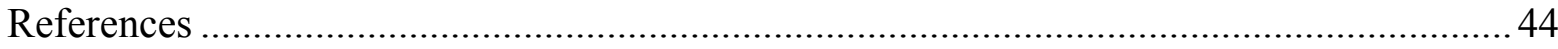




\section{List of Tables}

Table 2.1 Principal Mass Loadings in the ZPPR-21 Cores $(\mathrm{kg})$...................................5

Table 2.2 Reference Configuration Data for ZPPR-21 …....................................6

Table 2.3 $\mathrm{k}_{\text {eff }}$ Results for ZPPR-21 Phases A through F from VIM Calculations .............9

Table 2.4 TWODANT $\left(\mathrm{S}_{24}\right) \mathrm{k}_{\mathrm{eff}}$ Values of ZPPR-21 Cores vs. Anisotropic

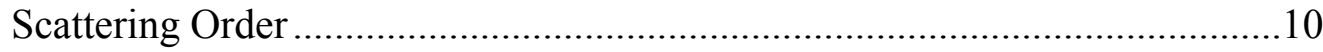

Table 2.5 TWODANT keff Values of ZPPR-21 Cores vs. Angular Quadrature Order....10

Table 2.6 TWODANT $\left(\mathrm{P}_{5} \mathrm{~S}_{24}\right) \mathrm{k}_{\text {eff }}$ Values of ZPPR-21 Cores vs. Anisotropic WithinGroup Scattering Cross Section Correction....................................................11

Table 2.7 Comparison of $\mathrm{k}_{\mathrm{eff}}$ Values of ZPPR-21 Cores Obtained from TWODANT Transport and DIF3D Diffusion Theory Calculations ..................................12

Table 2.8 Comparison of Leakage Fraction and Main Reaction Rates between TWODANT Transport and DIF3D Diffusion Theory Solutions for ZPPR21 Cores

Table 2.9 Comparison of Leakage Fraction and Main Reaction Rates between TWODANT $\mathrm{P}_{1} \mathrm{~S}_{16}$ and DIF3D Diffusion Theory Solutions vs. Core Size (ZPPR-21A Compositions)

Table 2.10 Reactivity Effects (pcm) of Deviations of TWODANT One-Group Cross Sections from VIM Result (ZPPR-21 Phase A through C)

Table 2.11 Reactivity Effects (pcm) of Deviations of TWODANT One-Group Cross Sections from VIM Results (ZPPR-21 Phase D through F) ..........................17

Table 2.12 Comparison of TWODANT $\mathrm{k}_{\mathrm{eff}}$ Results with Benchmark Values .20

Table 2.13 $\mathrm{k}_{\text {eff }}$ Results of ZPPR-21 Cores Obtained with Different Group Collapsing Methods

Table 3.1 $\mathrm{k}_{\text {eff }}$ Results of ZPPR-15 Phase A Loading Number 15 Obtained with Various Computational Models

Table 3.2 Core Region $\mathrm{k}_{\infty}$ Values of ZPPR-15 Master Drawers 103 and 201 Obtained with Various Computational Models 32

Table $3.3 \mathrm{k}_{\infty}$ Results of ZPPR-15 Master Drawers 201 for Different Axial Blanket Models. 34

Table 3.4 Heterogeneity Effect of ZPPR-15 Master Drawers 501 (Radial Blanket) Obtained with Various Computational Models .34

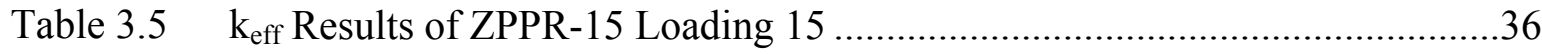




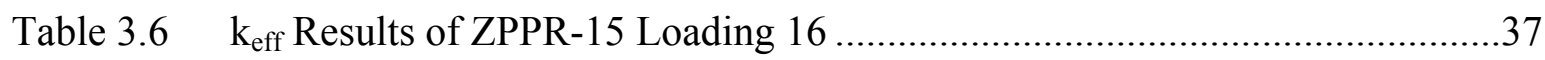

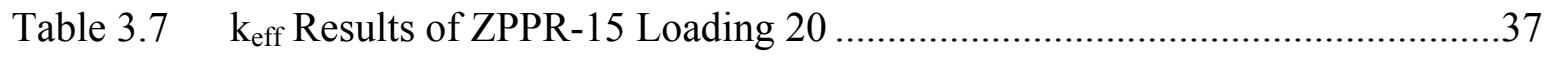

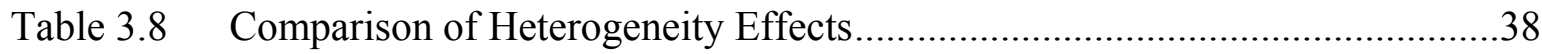

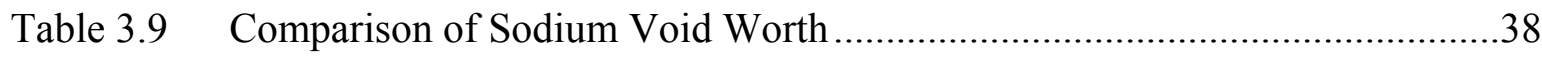

Table 3.10 Comparison of ZPPR-15 Loading $16 \mathrm{k}_{\mathrm{eff}}$ Results........................................40

Table 3.11 Comparison of ZPPR-15 Loading $20 \mathrm{k}_{\text {eff }}$ Results......................................40 


\section{List of Figures}

Figure 2.1 Benchmark Model Geometry for ZPPR-21A (Reference 5) .........................7

Figure 2.2 Leakage Fraction and Deviation of DIF3D k $\mathrm{eff}_{\mathrm{ef}}$ Value from TWODANT

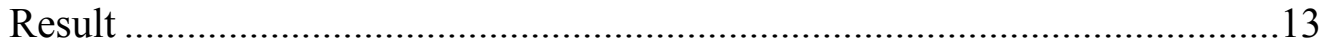

Figure 2.3 Effects of Separate Spectral Transition Zone between Core and Reflector.....14

Figure 2.4 Deviation of TWODANT $\mathrm{k}_{\mathrm{eff}}$ Value Estimated with Zero Leakage Error from VIM $k_{\text {eff }}$ Value vs. Fraction of Main Nuclides in Heavy Metal..............18

Figure 3.1 ZPPR-15 Loading 15 Reference Critical Planar Configuration ....................24

Figure 3.2 ZPPR-15 Loading 15 Reference Critical R-Z Dimensions [cm] .................25

Figure 3.3 Realistic View (X-Z) of the Double-Fuel-Column Drawers (Master Drawer 201, Unit in $\mathrm{cm})$.........................................................................26

Figure 3.4 Plate Loading Pattern (X-Z) for Material in the Single-Fuel-Column

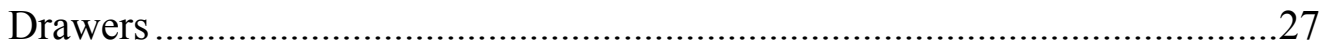

Figure 3.5 Plate Loading Pattern (X-Z) for Material in the Double-Fuel-Column

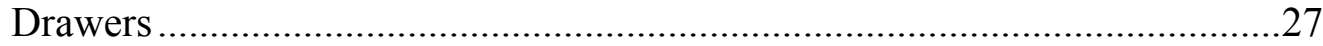

Figure 3.6 Plate Loading Pattern (X-Z) for Material in the Radial Blanket Drawers ......28

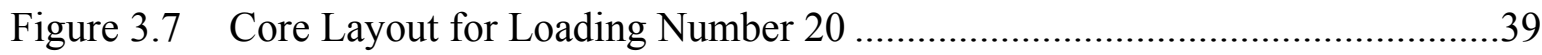




\section{Executive Summary}

A study was performed to validate the existing tools for fast reactor neutronics analysis against previous critical experiments. The six benchmark problems for the ZPPR-21 critical experiments phases A through F specified in the Handbook of Evaluated Criticality Safety Benchmark Experiments were analyzed. Analysis was also performed for three loading configurations of the ZPPR-15 Phase A experiments. As-built core models were developed in $\mathrm{XYZ}$ geometries using the reactor loading records and drawer master information.

Detailed Monte Carlo and deterministic transport calculations were performed, along with various modeling sensitivity analyses. The Monte Carlo simulations were carried out with the VIM code with continuous energy cross sections based on the ENDF/B-V.2 data. For deterministic calculations, region-dependent 230-group cross sections were generated using the ETOE-2/MC 2 -2/SDX code system, again based on the ENDF/B-V.2 data. Plate heterogeneity effects were taken into account by SDX unit cell calculations. Core calculations were performed with the TWODANT discrete ordinate code for the ZPPR-21 benchmarks, and with the DIF3D nodal transport option for the ZPPR-15 experiments.

For all six ZPPR-21 configurations where the Pu-239 concentration varies from 0 to 49 w/o and the U-235 concentration accordingly varies from 62 to $0 \mathrm{w} / \mathrm{o}$, the core multiplication factor determined with a 230-group TWODANT calculation agreed with the VIM Monte Carlo solution within $0.20 \% \Delta \mathrm{k}$, and there was no indication of any systematic bias. The quality of principal cross sections generated with the $\mathrm{MC}^{2}-2$ code was comparable to that of VIM cross sections. The overall reactivity effect due to the errors in the 230-group principal cross sections was estimated to be less than $0.05 \% \Delta \mathrm{k}$. The statistics of the differences between calculated values and specified benchmark experimental values showed similar bias (from $-0.28 \% \Delta \mathrm{k}$ to $0.33 \% \Delta \mathrm{k}$ ) for $\mathrm{MC}^{2}-2$ /TWODANT and VIM. This result suggests that the criticality prediction accuracy of $\mathrm{MC}^{2}-2 / \mathrm{TWODANT}$ is comparable to VIM.

Investigation of group collapsing methods showed that direct generation of broad-group cross sections from $\mathrm{MC}^{2}-2$ calculations was not adequate for analysis of ZPPR-21 assemblies. Scalar flux weighting for all cross sections, including anisotropic cross sections, was not sufficiently accurate, either. The use of higher flux moments for anisotropic scattering cross section collapsing reproduced the fine-group results with broad-group calculations.

The ZPPR-15 analyses, starting from detailed as-built plate geometries, showed that the plate heterogeneity effect was as large as $1.3 \% \Delta \mathrm{k}$. Through a series of sensitivity studies, a procedure to generate effective cross sections was developed based on one-dimensional SDX unit cell calculations. With this procedure to account for the plate heterogeneity effect, the core multiplication factor determined with a 230-group DIF3D nodal transport calculation agreed with the VIM Monte Carlo solution within $0.12 \% \Delta \mathrm{k}$. It was however observed that the calculated values consistently underestimated the criticality by $0.32 \% \Delta \mathrm{k}$ to $0.43 \% \Delta \mathrm{k}$. The sodium void worths determined from VIM Monte Carlo and DIF3D nodal transport calculations 
were also very close to each other, but both predictions overestimated the measured void worth by $\sim 0.1 \% \Delta \mathrm{k}$, which amounted to $\sim 40 \%$ of the measured value. Further investigation is needed to identify the reason for this discrepancy between calculated and measured sodium void worths.

In summary, for all nine core configurations of ZPPR-21 and ZPPR-15 analyzed in this study, the deterministic transport solutions showed good agreement with Monte Carlo results. These results indicate that the existing deterministic methods for multigroup cross section generation and core calculation are adequate to use in the initial design stage of Advanced Burner Reactors, for which the startup fuel is expected to be conventional plutonium fuel. However, further verification/validation studies need to be performed for transmutation fuel to assess the impact of relatively large amount of minor actinides. In addition, to take into account the multi-dimensional heterogeneity effects properly, the current homogenization scheme based on one-dimensional cell calculation needs to be improved. 


\section{Introduction}

The Advanced Burner Reactor (ABR) based on a fast spectrum is one of the three major technologies to be demonstrated in the Global Nuclear Energy Partnership (GNEP) program. The primary mission of the ABR is to demonstrate the transmutation of transuranics (TRU) recovered from light water reactor (LWR) spent fuel, and hence the benefits to nuclear waste management of closure of the fuel cycle. Design of the ABR and confirmation of its safety require a validated set of analysis tools for representing neutronics, irradiation behavior, thermal-hydraulic behavior, structural and mechanical behavior, and chemical interaction and species transport phenomena under steady-state and transient conditions. Characterization of prediction uncertainties is central to the validation of the analysis tools.

Under the ABR technology development program of GNEP, work initiated in the fiscal year 2007 to validate the ANL neutronics analysis tools and nuclear data for ABR design applications, but with a vey limited work scope. As an initial effort, a numerical benchmark problem based on the reference metal fuel core concept of $250 \mathrm{MWt}$ Advanced Burner Test Reactor (ABTR) and the six ZPPR-21 critical assemblies were analyzed [1]. Preliminary tests of the ENDF/B-VII.0 data were also performed using a set of fast system criticality benchmark problems. As a continued effort, additional analyses were performed for three loading configurations of the ZPPR-15 experiments.

The ZPPR-15 experiments were conducted from April 1985 through July 1986 under the Integral Fast Reactor (IFR) Benchmark Physics Test Program [2,3]. The focus of the program was to provide experimental support for core designs using metallic alloy fuel. The basis for the critical assembly was a 330 MWe sodium-cooled fast reactor. This reference design had a twozone, 2500-liter conventional core with a single row of radial blanket assemblies. Tests included diverse reactor physics measurements such as criticality, void worth, region-wise spectral indices, reaction rates, control rod worth, and reactivity coefficients.

The ZPPR-15 experiments were performed in four phases. Each phase was marked by a particular composition of the reference assembly, with the last three being representations of the three stages of the IFR fuel cycle. Phase A was a clean physics assembly containing only plutonium, depleted uranium, stainless steel and sodium without zirconium. The succeeding phases had zirconium added to the core composition, enabling the zirconium effect to be separated out. In this study, three loading configurations of the ZPPR-15 Phase A benchmarks were analyzed: initial criticality configuration (loading 15); a reference configuration for sodium void worth measurement (loading 16); and a configuration with an 18-inch sodium void in part of the inner core (loading 20).

These experiments were previously analyzed in 1989 [3]. However, the analysis was mainly performed with three-dimensional nodal diffusion theory and 21-group cross sections, to be consistent with the core analysis methods at that time. Although the same design tools are still being used, they have been modified continually for last two decades. More importantly, the 
significant improvements in computing environments now allow the use of more detailed models for routine design calculations. Therefore, the ZPPR-15 experiments were reanalyzed using the utmost capabilities of current analysis tools. As-built core models were developed in XYZ geometries using the reactor loading records and drawer master information. Deterministic calculation models were developed by homogenizing each drawer and by accounting for the plate heterogeneities in the generation of effective multigroup cross sections. Detailed Monte Carlo and deterministic transport calculations were performed, along with various modeling sensitivity analyses.

The purpose of this report is to document the results of ZPPR-15 and ZPPR-21 experiment analyses performed this year. The ZPPR-21 results are included for completeness although some of the key results were reported in a previous report [1].

Section 2 presents the Monte Carlo and deterministic analysis results of ZPPR-21 critical experiments. The results of various modeling sensitivity analyses are also discussed. The Monte Carlo and deterministic analysis results of the ZPPR-15 Phase A experiments are discussed in Section 3. The conclusions are given in Section 4. 


\section{Analysis of ZPPR-21 Critical Experiment Benchmarks}

Based on Monte Carlo analyses with the VIM code [4], criticality benchmark problems were previously developed for the ZPPR-21 critical experiments phases A through F [5-7]. These benchmark problems are specified in RZ geometry with region-averaged compositions. In order to test the performance of deterministic design tools, these six ZPPR-21 benchmark problems were analyzed. Multigroup cross sections were generated using the ETOE-2/MC $\mathrm{MC}^{2}$ code system $[8,9]$ based on the ENDF/B-V.2 data. Core calculations were performed with the TWODANT discrete ordinate transport code [10]. The predicted multiplication factors were compared with the values provided in the benchmark specifications in References 5 to 7 and VIM Monte Carlo solutions. The analysis methods and results of these ZPPR critical benchmark problems are discussed in this section.

\subsection{Description of ZPPR-21 Critical Experiments}

ZPPR Assembly 21 consisted of a series of six criticality benchmark cores built in the ZPPR facility to provide data for validating criticality calculations for systems likely to arise in the Integral Fast Reactor (IFR) fuel processing operations. The assemblies were graphite reflected, and different mixtures of plutonium and uranium were used in mock-up Pu-U-zirconium fuel. The first of these configurations, ZPPR-21A, was built with only plutonium fuel to take advantage of the inherent neutron source of $\mathrm{Pu}-240$. Then enriched uranium was progressively substituted for plutonium in Phases 21B through 21E. The final configuration, ZPPR-21F, had an all-uranium fuel loading and required an external neutron source to assist in the approach to critical. Experiments in Assembly 21 were performed between June and September 1990.

All six configurations have the same core volume, which approximates a cylinder of about 40 $\mathrm{cm}$ height and a stepped radial boundary of about $19 \mathrm{~cm}$ effective radius. Mass loadings of the principal core constituents in the six ZPPR 21 reference configurations reported in Reference 15 are given in Table 2.1. Note that the zirconium content remained constant through all the phases, while the U-238 and steel varied by only small amounts.

Table 2.1 Principal Mass Loadings in the ZPPR-21 Cores (kg) ${ }^{\text {a) }}$

\begin{tabular}{|c|r|r|r|r|r|r|}
\hline Material & $21 \mathrm{~A}$ & $21 \mathrm{~B}$ & $21 \mathrm{C}$ & $21 \mathrm{D}$ & $21 \mathrm{E}$ & $21 \mathrm{~F}$ \\
\hline $\mathrm{Pu}-239$ & 94.4 & 74.9 & 55.4 & 35.9 & 16.4 & 0.0 \\
\hline $\mathrm{Pu}-240$ & 5.9 & 4.9 & 4.0 & 3.1 & 2.2 & 0.0 \\
\hline $\mathrm{Pu}-241$ & 0.20 & 0.18 & 0.16 & 0.14 & 0.12 & 0.00 \\
\hline $\mathrm{U}-235$ & 0.2 & 20.5 & 61.1 & 81.4 & 122.0 & 162.6 \\
\hline $\mathrm{U}-238$ & 90.4 & 91.6 & 94.0 & 95.2 & 97.6 & 98.3 \\
\hline $\mathrm{Zr}$ & 30.7 & 30.7 & 30.7 & 30.7 & 30.7 & 30.7 \\
\hline Steel $^{\text {b) }}$ & 74.7 & 80.5 & 78.8 & 84.2 & 82.0 & 79.5 \\
\hline
\end{tabular}

a) Minor quantities of $\mathrm{C}, \mathrm{O}, \mathrm{Al}, \mathrm{Si}, \mathrm{P}, \mathrm{Cl}, \mathrm{S}, \mathrm{Cu}, \mathrm{Mo}, \mathrm{U}-234, \mathrm{U}-236, \mathrm{Pu}-238$, and Am-241 are not shown.

b) Steel includes Fe, Ni, Cr, and Mn. 
The reactivity of the reference critical configuration for each of the ZPPR-21 phases was obtained from an inverse kinetics analysis of the power history when the fuel control rods were fully inserted and the $\mathrm{B}_{4} \mathrm{C}$ shim rods were fully withdrawn. Reference configuration data for the six mixed-fissile phases are given in Table 2.2. The benchmark models were developed based on the VIM analyses for the as-built models in References 5 to 7, where all the experimental details were represented. The key features retained in the benchmark models are the region-averaged compositions, region volumes, and the global RZ geometry. The radial dimensions of the benchmark model are determined by the total cross-sectional area of the matrix positions included in each region, i.e., radii of cylindrical boundaries conserve cross-sectional areas of the corresponding regions in the detailed model. Axial dimensions of each region conserve the region volume. Masses of the constituents within these regions are then homogenized to produce the region-averaged compositions, thereby conserving material masses within each region. The VIM output edits for the as-built model included the region-average compositions, which were extracted to construct the benchmark model.

Table 2.2 Reference Configuration Data for ZPPR-21

\begin{tabular}{|l|c|c|c|c|c|c|}
\hline Configuration & $21 \mathrm{~A}$ & $21 \mathrm{~B}$ & $21 \mathrm{C}$ & $21 \mathrm{D}$ & $21 \mathrm{E}$ & $21 \mathrm{~F}$ \\
\hline Loading No. & 18 & 30 & 34 & 49 & 57 & 66 \\
\hline Date & $07 / 11 / 1990$ & $07 / 24 / 1990$ & $08 / 01 / 1990$ & $08 / 10 / 1990$ & $08 / 21 / 1990$ & $09 / 04 / 1990$ \\
\hline Temperature, ${ }^{\circ} \mathrm{C}$ & 26 & 26 & 25 & 24 & 23 & 22 \\
\hline Experimental $\mathrm{k}_{\mathrm{eff}}$ & 1.00023 & 1.00009 & 0.99928 & 1.00135 & 1.00092 & 1.00056 \\
\hline Adjusted & 1.00085 & 1.00071 & 0.99980 & 1.00179 & 1.00124 & 1.00057 \\
Experimental $\mathrm{k}_{\mathrm{eff}}$ & \pm 0.00150 & \pm 0.00144 & \pm 0.00148 & \pm 0.00152 & \pm 0.00166 & \pm 0.00177 \\
\hline Benchmark & 0.9967 & 0.9897 & 0.9998 & 1.0018 & 1.0012 & 0.9998 \\
Model $_{\text {eff }}$ & \pm 0.0026 & \pm 0.0023 & \pm 0.0023 & \pm 0.0024 & \pm 0.0024 & \pm 0.0025 \\
\hline
\end{tabular}

References 5 to 7 illustrate in detail the reduction procedures to develop the proposed benchmark problems in a concise, easy-to-reproduce RZ geometry benchmark model and to derive the core eigenvalue for each benchmark problem. The experimental $k_{\text {eff }}$ in Table 2.2 was adjusted to account for the effects of matrix interface gap, matrix tube pitch gap, room return neutrons, impurities (including corrosion impurities), and Ke-F coating material for the depleteduranium plate, which are not included in the benchmark specifications. The adjusted experimental $\mathrm{k}_{\mathrm{eff}}$ was further corrected by the reactivity effects corresponding to the geometry transformation from the as-built model to the RZ geometry benchmark model, yielding the benchmark model $\mathrm{k}_{\text {eff }}$ value that is included in the last row of Table 2.2 along with an uncertainty of one standard deviation. The benchmark eigenvalues account for the cylinderization effect, the heterogeneity effect (plate, drawer, and matrix tube), and the homogenization effect of each region. Even with this significant simplification, the transport effect, energy group effect, energy self-shielding and material interference, modeling concerns, and basic cross section effect can be addressed with the benchmark model. 
The benchmark model geometry for ZPPR-21 Phase A is depicted in Figure 2.1. Except for the thicknesses of the radial reflector and voided drawers, all the benchmark geometries remain the same throughout all the phases of ZPPR-21. The radial reflector thickness is $8.05415 \mathrm{~cm}$ for $21 \mathrm{~A}, 12.59858 \mathrm{~cm}$ for $21 \mathrm{~B}, 9.95114 \mathrm{~cm}$ for $21 \mathrm{C}, 16.06981 \mathrm{~cm}$ for $21 \mathrm{D}, 12.79081 \mathrm{~cm}$ for $21 \mathrm{E}$, and $8.77122 \mathrm{~cm}$ for $21 \mathrm{~F}$.

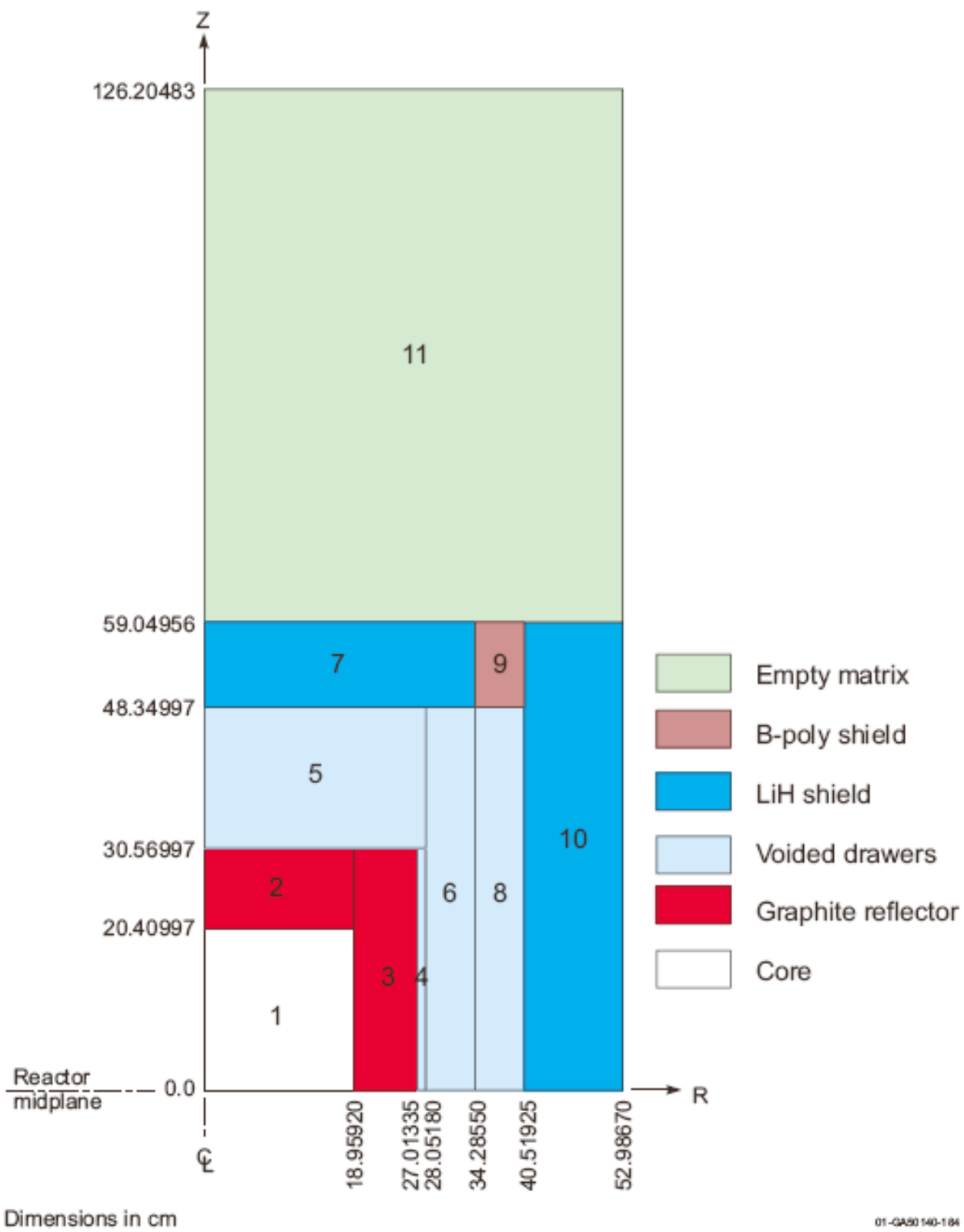

Figure 2.1 Benchmark Model Geometry for ZPPR-21A (Reference 5) 


\subsection{Cross Section Generation}

Using the ETOE-2 code, the $\mathrm{MC}^{2}-2$ libraries were prepared based on ENDF/B-V.2 data. In the preparation of the $\mathrm{MC}^{2}-2$ libraries, wide and extremely weak resonances were pre-processed and represented by the ultra-fine-group (2082 groups) energy structure of $\mathrm{MC}^{2}-2$. Detailed criteria on screening of wide and weak resonances are discussed in Reference 11. The other resonances were modeled by their resonance parameters, and their self-shielding effects were explicitly evaluated in the $\mathrm{MC}^{2}-2$ calculation.

For each configuration, region-dependent 230-group cross sections were generated using the $\mathrm{MC}^{2}-2$ code. $\mathrm{MC}^{2}-2$ calculations were performed with the consistent $\mathrm{P}_{1}$ approximation, and anisotropic scattering cross sections were generated for Legendre orders up to five. A critical buckling search was performed for the active core region.

For non-fueled regions, fixed source calculations were performed with an estimated leakage spectrum from adjacent regions. For example, the $\mathrm{MC}^{2}-2$ calculations for regions 2 and 3 in Figure 2.1 were performed with an external source representing the leakage spectrum of region 1. Two paths of neutron leakage were assumed; one sequence of 1, 2, 5, 7, and 11 and the other sequence of $1,3,4,6,8$, and 10 .

Since there was a significant amount of steel in the critical assemblies, it was necessary to model resonance-like Fe scattering cross sections in the energy above the resolved resonance energy region. Using the SHIELD program [12], the smooth cross section library of $\mathrm{MC}^{2}-2$ was generated for each specific composition and used in the subsequent region-wise $\mathrm{MC}^{2}-2$ calculation. The resulting cross section set for each region was augmented for all the regions of an assembly using the SDX code [8].

For TWODANT transport calculations, the higher order within-group scattering cross sections were modified to be consistent with the total cross section used in TWODANT. In the consistent $\mathrm{P}_{1}$ or $\mathrm{B}_{1}$ calculation of $\mathrm{MC}^{2}-2$ with an extended transport approximation, the multigroup cross sections for each flux moment are weighted with the corresponding flux moment, yielding a consistent set of multigroup equations. On the other hand, the TWODANT code uses total cross sections weighted with a scalar flux as most other transport codes do. That is, the consistent $\mathrm{P}_{\mathrm{N}}$ approximation is used. Therefore, the higher order scattering cross sections need to be modified to be consistent with the total cross section weighted with scalar flux as

$$
\tilde{\sigma}_{n g^{\prime} \rightarrow g}=\sigma_{n g^{\prime} \rightarrow g}+\left(\sigma_{t 0 g}-\sigma_{t n g}\right) \delta_{g g^{\prime}}
$$

where $\sigma_{n g^{\prime} \rightarrow g}$ is the $n$-th order scattering cross section from group $g^{\prime}$ to $g, \sigma_{t 0 g}$ is the scalar flux weighted total cross section, $\sigma_{\text {tng }}$ is the total cross section weighted with the $n$-th flux moment, and $\delta_{g g^{\prime}}$ is Kronecker's delta. 


\subsection{Reference VIM Monte Carlo Calculations}

Reference solutions were obtained from VIM Monte Carlo calculations with the cross sections based on ENDF/B-V.2 data. Thirty million histories were used per assembly. The $\mathrm{k}_{\mathrm{eff}}$ values are summarized in Table 2.3. The cited VIM $k_{\text {eff }}$ values were obtained from the combined estimator of analog and track length estimators. The standard deviation was rounded up from the fifth decimal point. For all six core configurations, the standard deviation of the Monte Carlo simulation is less than or equal to $20 \mathrm{pcm} \Delta \mathrm{k}$. With such a small standard deviation, the isotopic reaction rate edited from the VIM calculations can be used for a detailed comparison with the TWODANT results.

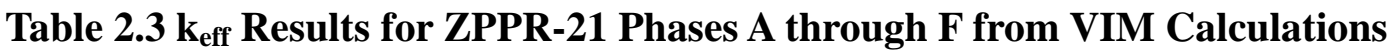

\begin{tabular}{|c|c|c|c|c|c|c|}
\hline Configuration & $\mathrm{A}$ & $\mathrm{B}$ & $\mathrm{C}$ & $\mathrm{D}$ & $\mathrm{E}$ & $\mathrm{F}$ \\
\hline Benchmark k $\mathrm{k}_{\text {eff }}$ & 0.9967 & 0.9897 & 0.9998 & 1.0018 & 1.0012 & 0.9998 \\
& \pm 0.0026 & \pm 0.0023 & \pm 0.0023 & \pm 0.0024 & \pm 0.0024 & \pm 0.0025 \\
\hline VIM k keff & 1.0000 & 0.9925 & 0.9979 & 0.9997 & 1.0000 & 1.0005 \\
(ENDF/B-V.2) & \pm 0.0002 & \pm 0.0002 & \pm 0.0002 & \pm 0.0002 & \pm 0.0002 & \pm 0.0002 \\
\hline Deviation, pcm $\Delta \mathrm{k}$ & 330 & 280 & -190 & -210 & -120 & 70 \\
\hline
\end{tabular}

The VIM $\mathrm{k}_{\text {eff }}$ results for configurations $\mathrm{C}$ to $\mathrm{F}$ agree with the benchmark $\mathrm{k}_{\mathrm{eff}}$ values within

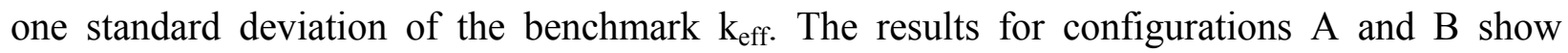
slightly larger deviations from the benchmark values; the deviations are between one and two standard deviations of the benchmark $\mathrm{k}_{\mathrm{eff}}$.

\subsection{TWODANT Core Calculation}

Fine mesh RZ geometry models were developed for TWODANT calculations with $1 \mathrm{~cm}$ radial and axial mesh intervals to eliminate mesh-related errors. For example, the TWODANT model for ZPPR-21A has 52 radial mesh nodes and 122 axial mesh nodes. Using these fine mesh models, sensitivity studies were first performed for anisotropic scattering order and angular quadrature. Then, the effects of anisotropic scattering correction and core-reflector interference were investigated.

\subsubsection{Effect of Scattering Order and Angular Quadrature}

Table 2.4 compares the TWODANT $\mathrm{k}_{\mathrm{eff}}$ results for different orders of anisotropic scattering approximation. All the results were obtained with an $\mathrm{S}_{\mathrm{N}}$ order of 24 (i.e., 78 different angles per octant) and triangular Chebyshev-Legendre built-in constants. The fifth and sixth columns list the $\mathrm{k}_{\text {eff }}$ differences from the $\mathrm{P}_{1}$ calculation results. 
Table 2.4 TWODANT $\left(\mathrm{S}_{24}\right) \mathrm{k}_{\text {eff }}$ Values of ZPPR-21 Cores vs. Anisotropic Scattering Order

\begin{tabular}{|c|c|c|c|c|c|}
\hline Scattering order & $\mathrm{P}_{1}$ & $\mathrm{P}_{3}$ & $\mathrm{P}_{5}$ & $\mathrm{P}_{3}-\mathrm{P}_{1}(\mathrm{pcm})$ & $\mathrm{P}_{5}-\mathrm{P}_{1}(\mathrm{pcm})$ \\
\hline $\mathrm{A}$ & 0.99192 & 0.99860 & 0.99873 & 668 & 681 \\
\hline $\mathrm{B}$ & 0.98747 & 0.99285 & 0.99293 & 538 & 546 \\
\hline $\mathrm{C}$ & 0.99131 & 0.99690 & 0.99698 & 559 & 567 \\
\hline $\mathrm{D}$ & 0.99596 & 1.00036 & 1.00042 & 440 & 446 \\
\hline $\mathrm{E}$ & 0.99545 & 1.00002 & 1.00008 & 457 & 463 \\
\hline & 0.99331 & 0.99843 & 0.99852 & 512 & 521 \\
\hline
\end{tabular}

It is noted that the $\mathrm{P}_{1}$ approximation significantly underestimates core $\mathrm{k}_{\text {eff }}$ values. This implies that the diffusion calculations with the transport-corrected diffusion coefficients are expected to significantly underestimate core $\mathrm{k}_{\mathrm{eff}}$ values for these configurations. Expansion up to the third Legendre order of anisotropic scattering yields almost converged core $k_{\text {eff }}$ values, within $13 \mathrm{pcm}$ from more refined $\mathrm{P}_{5}$ calculation results. There is no essential difference between $\mathrm{P}_{3}$ and $\mathrm{P}_{5}$ scattering expansion results. These results suggest that at least a $\mathrm{P}_{3}$ approximation needs to be used for ZPPR-21 analyses. This is a characteristic of such small cores as the ZPPR-21 assemblies.

Table 2.5 presents the dependency of TWODANT $\mathrm{k}_{\text {eff }}$ values on angular quadrature. The triangular Chebyshev-Legendre built-in constants were used for $\mathrm{S}_{24}$ and $\mathrm{S}_{32}$, while the traditional built-in constants were used for $\mathrm{S}_{16}$. The value in each parenthesis designates the $\mathrm{k}_{\text {eff }}$ difference from the $\mathrm{S}_{16}$ result for each Legendre scattering order. As can be seen, the $\mathrm{k}_{\text {eff }}$ value almost converges to an asymptotic value when the quadrature order is greater than or equal to 24 . Based on this result, $\mathrm{S}_{24}$ was selected for the angular quadrature.

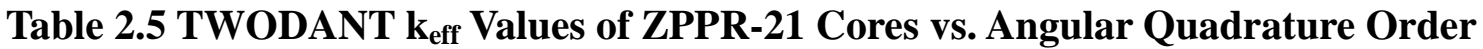

\begin{tabular}{|c|c|c|c|c|c|}
\hline Scattering order & \multicolumn{3}{|c|}{$\mathrm{P}_{3}$} & \multicolumn{2}{c|}{$\mathrm{P}_{5}$} \\
\hline Angular quadrature & $\mathrm{S}_{16}$ & $\mathrm{~S}_{24}$ & $\mathrm{~S}_{32}$ & $\mathrm{~S}_{16}$ & $\mathrm{~S}_{24}$ \\
\hline $\mathrm{A}$ & 0.99899 & $0.99860(-39)^{\mathrm{a})}$ & $0.99855(-44)$ & 0.99912 & $0.99873(-39)$ \\
\hline $\mathrm{B}$ & 0.99317 & $0.99285(-32)$ & $0.99281(-36)$ & 0.99321 & $0.99293(-28)$ \\
\hline $\mathrm{C}$ & 0.99724 & $0.99690(-34)$ & $0.99685(-39)$ & 0.99732 & $0.99698(-34)$ \\
\hline $\mathrm{D}$ & 1.00062 & $1.00036(-26)$ & $1.00033(-29)$ & 1.00067 & $1.00042(-25)$ \\
\hline $\mathrm{E}$ & 1.00030 & $1.00002(-28)$ & $0.99998(-32)$ & 1.00035 & $1.00008(-27)$ \\
\hline $\mathrm{F}$ & 0.99876 & $0.99843(-33)$ & $0.99839(-37)$ & 0.99885 & $0.99852(-33)$ \\
\hline
\end{tabular}

a) Deviation from $\mathrm{S}_{16}$ results in pcm $\Delta \mathrm{k}$.

\subsubsection{Effect of Anisotropic Scattering Cross Section Correction}

The effect of the anisotropic within-group scattering cross section correction was examined. Table 2.6 summarizes the correction effect determined from 230-group $\mathrm{P}_{5} \mathrm{~S}_{24}$ TWODANT 
calculations. As can be seen, the effect of the anisotropic scattering correction is noticeable even in the 230-group structure; the correction effect is $-218 \mathrm{pcm} \Delta \mathrm{k}$ on average. Since the fundamental flux weighted total cross section is used as a total cross section in TWODANT, the corrected cases correspond to the consistent $\mathrm{P}_{5}$ approximation. Compared to the VIM Monte Carlo solutions, the TWODANT results without correction of anisotropic within-group scattering cross sections overestimate the core $\mathrm{k}_{\mathrm{eff}}$ by $170 \mathrm{pcm} \Delta \mathrm{k}$ on average, while the results with the correction underestimate the core $\mathrm{k}_{\mathrm{eff}}$ by $50 \mathrm{pcm} \Delta \mathrm{k}$ on average.

Table 2.6 TWODANT $\left(\mathrm{P}_{5} \mathrm{~S}_{24}\right) \mathrm{k}_{\text {eff }}$ Values of ZPPR-21 Cores vs. Anisotropic Within-Group Scattering Cross Section Correction

\begin{tabular}{|c|c|c|c|c|}
\hline Configuration & VIM & No Correction & Correction & Difference $(\mathrm{pcm})$ \\
\hline A & $1.0000 \pm 0.0002$ & 1.00127 & 0.99873 & -254 \\
\hline B & $0.9925 \pm 0.0002$ & 0.99506 & 0.99293 & -213 \\
\hline C & $0.9979 \pm 0.0002$ & 0.99931 & 0.99698 & -233 \\
\hline D & $0.9997 \pm 0.0002$ & 1.00225 & 1.00042 & -183 \\
\hline E & $1.0000 \pm 0.0002$ & 1.00199 & 1.00008 & -191 \\
\hline F & $1.0005 \pm 0.0002$ & 1.00084 & 0.99852 & -232 \\
\hline \multicolumn{2}{|r|}{ VIM-TWODANT ${ }^{\text {a) }}$} & $-0.0017 \pm 0.0009$ & $0.0005 \pm 0.0011$ & \\
\hline
\end{tabular}

a) Mean \pm one standard deviation.

\subsubsection{Transport Effect}

Table 2.7 compares the TWODANT results and DIF3D finite difference diffusion theory [13] results. Both codes used the same cross section set and the same mesh arrangement. Thus, the large difference between the two solutions can be attributed to the transport effect. In as small a core as ZPPR-21, where the transport effect is large, the diffusion theory approximation should be applied with caution. Comparing the results in Table 2.7 with the TWODANT solutions with $\mathrm{P}_{1}$ scattering order in Table 2.4 , it can be seen that linearly anisotropic scattering comprises only $7 \%$ of the total transport effect. The remaining $93 \%$ of the transport effect comes from the neutron streaming effect, which is not considered in diffusion theory.

Table 2.7 Comparison of $k_{\text {eff }}$ Values of ZPPR-21 Cores Obtained from TWODANT Transport and DIF3D Diffusion Theory Calculations

\begin{tabular}{|c|c|c|c|}
\hline Configuration & TWODANT $\mathrm{P}_{5}$ & DIF3D FDM & Difference $(\% \Delta \mathrm{k})$ \\
\hline $\mathrm{A}$ & 0.99873 & 0.90010 & -9.863 \\
\hline $\mathrm{B}$ & 0.99293 & 0.91406 & -7.887 \\
\hline $\mathrm{C}$ & 0.99698 & 0.91395 & -8.303 \\
\hline $\mathrm{D}$ & 1.00042 & 0.93424 & -6.618 \\
\hline $\mathrm{E}$ & 1.00008 & 0.93066 & -6.942 \\
\hline $\mathrm{F}$ & 0.99852 & 0.92054 & -7.798 \\
\hline
\end{tabular}


The main difference between transport and diffusion theory calculations is the difference in neutron leakage treatment, and thus the leakage effects were examined in detail. Table 2.8 compares the leakage fractions between total effective neutron losses of TWODANT and DIF3D solutions. The reactivity effects of the differences in leakage and main reactions between DIF3D and TWODANT solutions are also provided. Both TWODANT and DIF3D solutions were normalized to the same production rate. As expected, the DIF3D diffusion theory solutions overestimate the neutron leakage by about 3 to $4 \%$. The overestimated leakage leads to underestimation of core reactivity by about 7 to $11 \% \Delta \rho$. The reactivity effects of the differences in fission, capture, and $(\mathrm{n}, 2 \mathrm{n})$ reactions are insignificant. These results suggest that the difference in the core flux distribution between TWODANT and DIF3D solutions is not significant.

To examine the leakage estimation by diffusion theory further, a parametric study was performed by increasing the active core size of ZPPR-21A arbitrarily in the radial direction with a fixed core height of $1 \mathrm{~m}$. Table 2.9 summarizes the leakage fractions and the reactivity effects of the differences in leakage and main reactions between DIF3D diffusion theory and TWODANT $\mathrm{P}_{1} \mathrm{~S}_{16}$ solutions. As can be seen, the difference in the leakage fraction between TWODANT and DIF3D solutions decreases with increasing core size, and the reactivity error of the DIF3D diffusion theory solution decreases noticeably with decreasing leakage fraction. The leakage fraction and deviation of the DIF3D $\mathrm{k}_{\text {eff }}$ value from the TWODANT solution are also shown in Figure 2.2 as a function of surface-to-volume ratio of the active core. The leakage fraction is approximately proportional to the surface-to-volume ratio, and thus the surface-tovolume ratio can serve as a rough indicator as to when it is necessary to utilize a transport theory solution for a given core size. The results in Figure 2.2 suggest that a core with a surface-tovolume ratio greater than 0.047 or a leakage fraction larger than 0.18 would generally demand the use of a transport theory solution in order to keep the deviation of the diffusion theory $\mathrm{k}_{\mathrm{eff}}$ value from the transport solution under $0.5 \% \Delta \rho$.

Table 2.8 Comparison of Leakage Fraction and Main Reaction Rates between TWODANT Transport and DIF3D Diffusion Theory Solutions for ZPPR-21 Cores

\begin{tabular}{|c|c|c|c|c|c|c|c|}
\hline \multicolumn{2}{|c|}{ Configuration } & $\mathrm{A}$ & $\mathrm{B}$ & $\mathrm{C}$ & $\mathrm{D}$ & $\mathrm{E}$ & $\mathrm{F}$ \\
\hline \multirow{2}{*}{$\begin{array}{c}\text { Leakage } \\
\text { Fraction }\end{array}$} & TWODANT & 0.5958 & 0.5702 & 0.5561 & 0.5251 & 0.5156 & 0.5128 \\
\cline { 2 - 8 } & DIF3D & 0.6367 & 0.6044 & 0.5936 & 0.5557 & 0.5491 & 0.5512 \\
\cline { 2 - 8 } & Difference & 0.0409 & 0.0342 & 0.0375 & 0.0306 & 0.0335 & 0.0384 \\
\hline \multirow{2}{*}{$\begin{array}{c}\text { Reactivity } \\
\text { Effect } \\
(\% \Delta \rho)\end{array}$} & Leakage & -11.08 & -8.70 & -9.17 & -6.99 & -7.44 & -8.52 \\
\cline { 2 - 8 } & Fission & 0.00 & -0.01 & 0.00 & -0.02 & -0.01 & 0.00 \\
\cline { 2 - 8 } & Capture & 0.11 & 0.02 & 0.06 & -0.06 & 0.00 & 0.04 \\
\cline { 2 - 8 } & $(\mathrm{n}, 2 \mathrm{n})$ & 0.00 & -0.01 & -0.01 & -0.01 & -0.01 & -0.01 \\
\hline
\end{tabular}

a) Reactivity effect of the deviation of the DIF3D solution from the TWODANT solution. 
Table 2.9 Comparison of Leakage Fraction and Main Reaction Rates between TWODANT $\mathrm{P}_{1} \mathrm{~S}_{16}$ and DIF3D Diffusion Theory Solutions vs. Core Size (ZPPR-21A Compositions)

\begin{tabular}{|c|c|c|c|c|c|c|c|}
\hline \multicolumn{2}{|c|}{ Core Radius (cm) } & 18.9592 & 50 & 75 & 100 & 125 & 150 \\
\hline \multicolumn{2}{|c|}{ Core Height $(\mathrm{cm})$} & 40.8199 & 100 & 100 & 100 & 100 & 100 \\
\hline \multirow{2}{*}{$\begin{array}{c}\text { Leakage } \\
\text { Fraction }\end{array}$} & TWODANT & 0.5961 & 0.2565 & 0.1825 & 0.1468 & 0.1270 & 0.1151 \\
\cline { 2 - 8 } & DIF3D & 0.6367 & 0.2698 & 0.1906 & 0.1526 & 0.1318 & 0.1192 \\
\cline { 2 - 8 } & Difference & 0.0407 & 0.0133 & 0.0081 & 0.0059 & 0.0048 & 0.0041 \\
\hline $\begin{array}{c}\text { Reactivity } \\
\text { Effect } \\
(\% \Delta \rho)\end{array}$ & Leakage & -11.02 & -0.96 & -0.48 & -0.32 & -0.25 & -0.21 \\
\cline { 2 - 8 } & Absorption & 0.11 & 0.09 & 0.06 & 0.05 & 0.04 & 0.04 \\
\cline { 2 - 8 } & $(\mathrm{n}, 2 \mathrm{n})$ & -0.00 & -0.10 & -0.08 & -0.07 & -0.07 & -0.06 \\
\hline
\end{tabular}

a) Reactivity effect of the deviation of the DIF3D solution from the TWODANT solution.

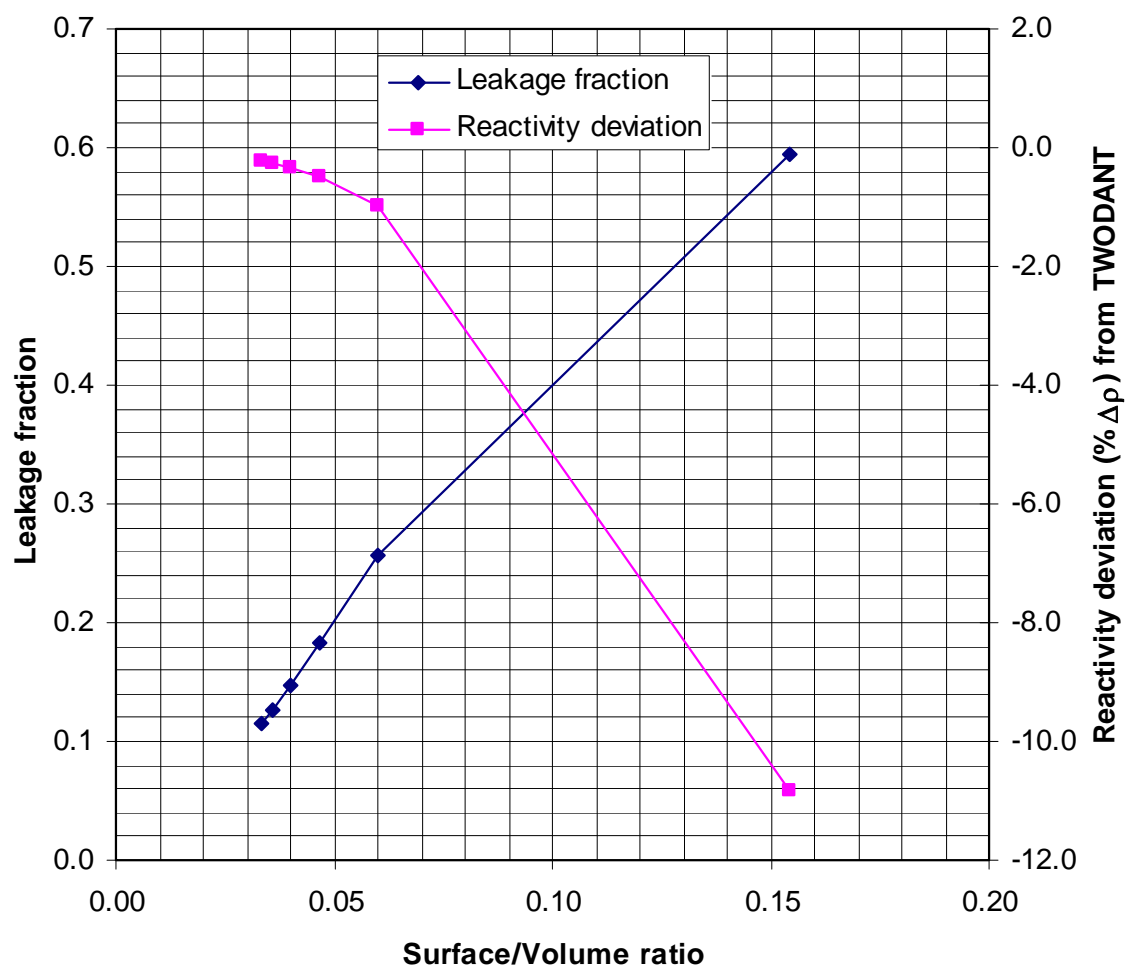

Figure 2.2 Leakage Fraction and Deviation of DIF3D $k_{\text {eff }}$ Value from TWODANT Result

\subsubsection{Core-Reflector Interface Effect}

Because of the graphite reflector in the ZPPR-21 assemblies, the spectrum of the neutrons reflected into the core is softer than that of the neutrons leaking into the reflector. Thus, U-238 would have an enhanced probability of capturing neutrons in the core of ZPPR-21 assemblies than in an infinite medium of the same core composition. In addition, since graphite does not have overlapping resonances with U-238, the background cross section for U-238 resonance absorption would be enhanced if the core-reflector interface were modeled in more detail. 
In order to account for both these effects, the core was divided into two regions, and a separate set of cross sections was generated for the region adjacent to the reflector using a mixture of core and reflector materials. Based on the observation that the average ratio of incoming to outgoing partial currents at the core-reflector interface of ZPPR-21 assemblies is 0.56 , the mixture was made of $\sim 64 \%$ core material and $\sim 36 \%$ of reflector material (by smearing core and reflector compositions in the ratio of 1 to 0.56 ). Two separate TWODANT calculations were performed using the mixture cross sections for the core region within one and two absorption mean free paths of the reflector.

The results are shown in Figure 2.3 as a function of Pu-239 fraction (w/o) in heavy metal. For the case in which the mixture cross sections are used within one mean free path of the reflector, the correction amounts to $18 \mathrm{pcm}$ for ZPPR-21F and $47 \mathrm{pcm}$ for ZPPR-21B. The absorption mean free path is $2.14 \mathrm{~cm}$ for ZPPR-21F and $2.54 \mathrm{~cm}$ for ZPPR-21B. When the region in which the mixture cross sections are used was increased to two mean free paths, the results were almost identical. On average, the core-reflector interference effect is $-34 \mathrm{pcm}$ when the mixture cross sections are used within one mean free path of the reflector, and $-39 \mathrm{pcm}$ when the mixture cross sections are used within two mean free paths of the reflector. These small effects are considered due to the hard neutron spectrum of the ZPPR-21 cores, which makes resonance absorption less important.

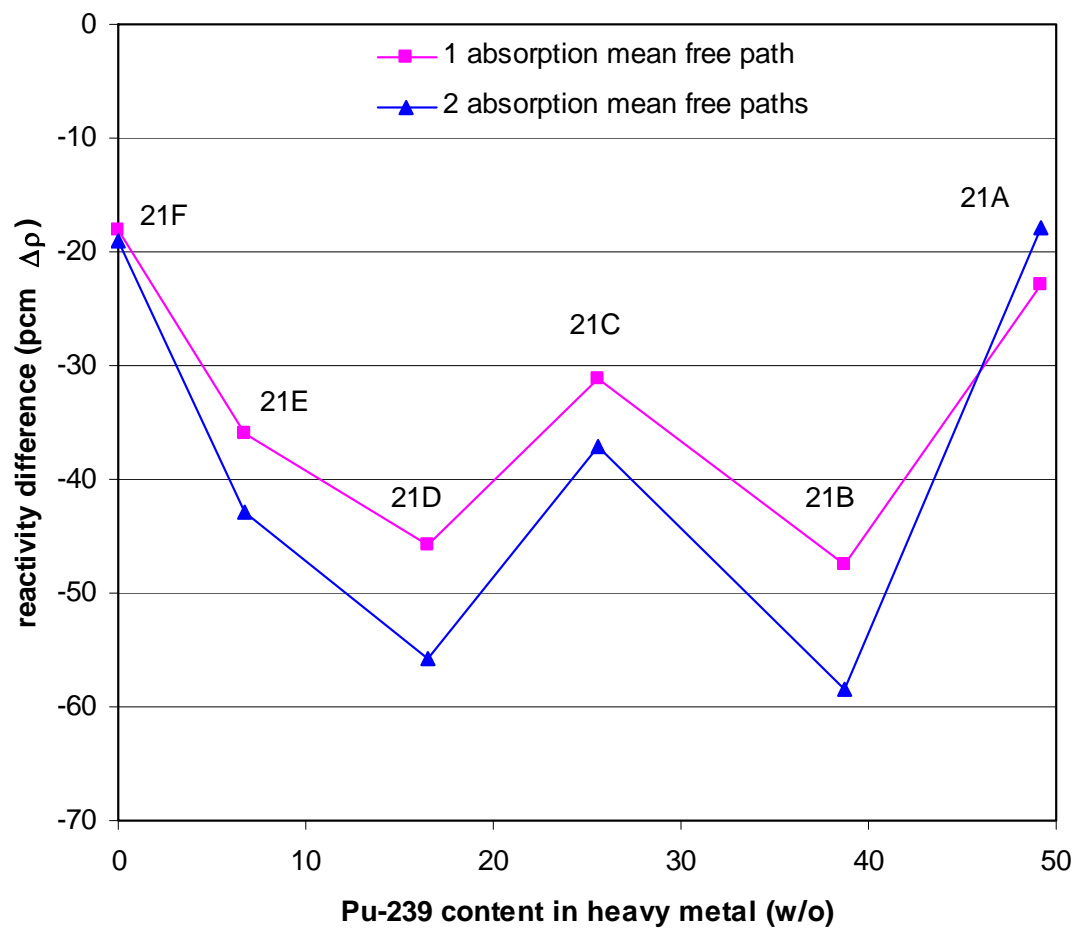

Figure 2.3 Effects of Separate Spectral Transition Zone between Core and Reflector 


\subsection{Verification of $M^{2}$-2/TWODANT against VIM Monte Carlo Calculation}

Based on the modeling studies discussed in the previous section, TWODANT $\mathrm{P}_{5} \mathrm{~S}_{24}$ transport calculation results obtained with 230-group cross sections generated with $\mathrm{MC}^{2}-2$ are considered to be the best estimates practically achievable with deterministic codes. These TWODANT results are compared in detail with the VIM Monte Carlo solutions. Isotopic contributions to the deviation between TWODANT and VIM core reactivity values were investigated. From 230-group $\mathrm{P}_{5} \mathrm{~S}_{24}$ TWODANT calculations, isotopic one-group cross sections were extracted, together with leakage rate. Isotopic one-group macroscopic cross sections determined with the track length estimator were also extracted from VIM calculations. Tables 2.10 and 2.11 summarize the reactivity effects caused by the deviations of TWODANT onegroup cross sections from VIM results. Only the isotopes that contribute more than $1 \mathrm{pcm}$ are listed. Scattering is expressed as the difference in macroscopic cross sections between TWODANT and VIM solutions, while the other reactions are given in terms of reactivity effects.

In Tables 2.10 and 2.11, " $\delta \mathrm{k} / \mathrm{k}$ (estimated)" is the deviation of the TWODANT reactivity value from the VIM result estimated with the isotopic reaction rates, and " $\mathrm{kk} / \mathrm{k}$ (calculated)" is the deviation determined with the $\mathrm{k}_{\text {eff }}$ values from the TWODANT and VIM calculations. The " $\delta \mathrm{k} / \mathrm{k}$ (estimated)" and " $\delta \mathrm{k} / \mathrm{k}$ (calculated)" values agree each other; the difference between them is $7 \mathrm{pcm}$ for the ZPPR-21C configuration and is less than $1 \mathrm{pcm}$ for the other cases. This result indicates that the neutron balance edits of TWODANT are consistent with the cross section edits. This implies that the cross sections generated with $\mathrm{MC}^{2}-2$ and subsequently corrected for withingroup anisotropic scattering are well balanced. Since TWODANT indirectly determines the removal cross sections from the total and within-group scattering cross sections, any inconsistency between total and partial cross sections or improper treatment of $(n, 2 n)$ cross sections would cause a non-negligible difference between $\mathrm{k}_{\text {eff }}$ values determined with isotopic cross sections and reaction balance.

The TWODANT reactivity values differ from VIM results by $-153,24,-94,56,8$, and -191 pcm $\Delta \rho$ for ZPPR-21A through $21 \mathrm{~F}$, respectively. The correlation coefficients between reactivity deviations and heavy metal contents are estimated to 0.00 for Pu-239, -0.06 for U-235, and 0.32 for U-238. That is, there is no noticeable correlation between reactivity deviation and heavy metal content. However, there is a strong correlation between reactivity deviation and reflector thickness. TWODANT underestimates the $\mathrm{k}_{\text {eff }}$ value for configurations $21 \mathrm{~A}, 21 \mathrm{C}$, and $21 \mathrm{~F}$, for which the reflector is thinner than $10.0 \mathrm{~cm}$, but overestimates the value for configurations $21 \mathrm{~B}$, 21D, and 21E, for which the reflector is thicker than $12 \mathrm{~cm}$. The correlation coefficient between reactivity deviation and reflector thickness is 0.94 . This result suggests that reflector cross sections or scattering cross sections of core material need to be improved for enhanced accuracy. However, this reflector effect would diminish in a power reactor, where the active core radius is much larger than the ZPPR-21 cores, because of reduced surface-to-volume ratio. In addition, a graphite reflector such as is used in the ZPPR-21 cores is not likely to be used in a power reactor. 
Table 2.10 Reactivity Effects (pcm) of Deviations of TWODANT One-Group Cross Sections from VIM Results (ZPPR-21 Phase A through C)

\begin{tabular}{|c|c|c|c|c|c|c|c|c|c|c|c|c|c|c|c|}
\hline \multirow{2}{*}{ Nuclide } & \multicolumn{5}{|c|}{$21 \mathrm{~A}$} & \multicolumn{5}{|c|}{$21 \mathrm{~B}$} & \multicolumn{5}{|c|}{$21 \mathrm{C}$} \\
\hline & $\mathrm{nu}$ & $\mathrm{n}, 2 \mathrm{n}$ & cap & fiss & scat* & $\mathrm{nu}$ & $\mathrm{n}, 2 \mathrm{n}$ & cap & fiss & scat* & $\mathrm{nu}$ & $\mathrm{n}, 2 \mathrm{n}$ & cap & fiss & scat* \\
\hline P-239 & -12 & -1 & 63 & -87 & -1 & -11 & 0 & 74 & -96 & 1 & -1 & 0 & 52 & -85 & -1 \\
\hline $\mathrm{P}-240$ & -1 & 0 & 42 & -1 & 0 & -1 & 0 & 56 & -3 & 0 & 0 & 0 & 32 & 0 & 0 \\
\hline $\mathrm{P}-241$ & 0 & 0 & 0 & 1 & 0 & 0 & 0 & 0 & 0 & 0 & 0 & 0 & 0 & -1 & 0 \\
\hline $\mathrm{P}-242$ & 0 & 0 & -1 & 0 & 0 & 0 & 0 & -1 & 0 & 0 & 0 & 0 & 0 & 0 & 0 \\
\hline Am-241 & 0 & 0 & -2 & 0 & 0 & 0 & 0 & -2 & 0 & 0 & 0 & 0 & 0 & 0 & 0 \\
\hline U-234 & & & & & & 0 & 0 & -1 & 0 & 0 & 0 & 0 & 0 & 0 & 0 \\
\hline U-235 & 0 & 0 & 0 & 0 & 0 & -3 & 0 & 4 & -1 & 0 & -2 & 1 & 12 & -30 & -1 \\
\hline U-236 & & & & & & 0 & 0 & 0 & 0 & 0 & 0 & 0 & 0 & 0 & 0 \\
\hline U-238 & -4 & -3 & 61 & -18 & 0 & -3 & -3 & 68 & -19 & 3 & -3 & 2 & 52 & -11 & -2 \\
\hline $\mathrm{Cr}$ & 0 & 0 & 0 & 0 & -4 & 0 & 0 & 0 & 0 & -2 & 0 & 0 & 1 & 0 & -3 \\
\hline $\mathrm{Ni}$ & 0 & 0 & 2 & 0 & -1 & 0 & 0 & 2 & 0 & 0 & 0 & 0 & 1 & 0 & -1 \\
\hline $\mathrm{Fe}$ & 0 & 0 & -9 & 0 & -5 & 0 & 0 & -12 & 0 & -3 & 0 & 0 & -8 & 0 & -4 \\
\hline Mo & 0 & 0 & 2 & 0 & 0 & 0 & 0 & 2 & 0 & 0 & 0 & 0 & 1 & 0 & 0 \\
\hline Mm-55 & 0 & 0 & 0 & 0 & 0 & 0 & 0 & -1 & 0 & 1 & 0 & 0 & 0 & 0 & 0 \\
\hline $\mathrm{Zr}$ & 0 & 0 & -8 & 0 & 6 & 0 & 0 & -9 & 0 & 9 & 0 & 0 & -6 & 0 & 6 \\
\hline Sum over nuclides, pcm & -17 & -5 & 150 & -105 & -5 & -18 & -4 & 180 & -120 & 10 & -6 & 3 & 136 & -127 & -6 \\
\hline Leakage, $\mathrm{pcm}$ & \multicolumn{5}{|c|}{-176} & \multicolumn{5}{|c|}{-15} & \multicolumn{5}{|c|}{-92} \\
\hline$\delta \mathrm{k} / \mathrm{k}$ (estimated), $\mathrm{pcm}$ & \multicolumn{5}{|c|}{-153} & \multicolumn{5}{|c|}{24} & \multicolumn{5}{|c|}{-88} \\
\hline$\delta \mathrm{k} / \mathrm{k}$ (calculated), $\mathrm{pcm}$ & \multicolumn{5}{|c|}{-153} & \multicolumn{5}{|c|}{24} & \multicolumn{5}{|c|}{-94} \\
\hline $\begin{array}{l}\delta \mathrm{k} / \mathrm{k} \text { (estimated w/o } \\
\text { leakage error), } \mathrm{pcm}\end{array}$ & \multicolumn{5}{|c|}{23} & \multicolumn{5}{|c|}{39} & \multicolumn{5}{|c|}{2} \\
\hline Reflector thickness $(\mathrm{cm})$ & \multicolumn{5}{|c|}{8.1} & \multicolumn{5}{|c|}{12.6} & \multicolumn{5}{|c|}{10.0} \\
\hline
\end{tabular}

\footnotetext{
$*\left(\Sigma_{\mathrm{s}, \text { TWODANT }}-\sum_{\mathrm{s}, \mathrm{VIM}}\right) \times 10^{5}\left[\mathrm{~cm}^{-1}\right]$
} 
Table 2.11 Reactivity Effects (pcm) of Deviations of TWODANT One-Group Cross Sections from VIM Results (ZPPR-21 Phase D through F)

\begin{tabular}{|c|c|c|c|c|c|c|c|c|c|c|c|c|c|c|c|}
\hline \multirow{2}{*}{ Nuclide } & \multicolumn{5}{|c|}{$21 \mathrm{D}$} & \multicolumn{5}{|c|}{$21 \mathrm{E}$} & \multicolumn{5}{|c|}{$21 \mathrm{~F}$} \\
\hline & $\mathrm{nu}$ & $n, 2 n$ & cap & fiss & scat* & $\mathrm{nu}$ & $\mathrm{n}, 2 \mathrm{n}$ & cap & fiss & scat* & $\mathrm{nu}$ & $n, 2 n$ & cap & fiss & scat* \\
\hline P-239 & 4 & 0 & 64 & -146 & 1 & 3 & 0 & 31 & -67 & 0 & & & & & \\
\hline P-240 & 0 & 0 & 47 & -2 & 0 & 0 & 0 & 21 & 0 & 0 & & & & & \\
\hline P-241 & 1 & 0 & 0 & -1 & 0 & 0 & 0 & 0 & -1 & 0 & & & & & \\
\hline P-242 & 0 & 0 & -1 & 0 & 0 & 0 & 0 & 0 & 0 & 0 & & & & & \\
\hline Am-241 & 0 & 0 & 0 & 0 & 0 & 0 & 0 & 1 & 0 & 0 & & & & & \\
\hline U-234 & 0 & 0 & 1 & 0 & 0 & 0 & 0 & 2 & 0 & 0 & 0 & 0 & 2 & 0 & 0 \\
\hline U-235 & -6 & 0 & 4 & 17 & 2 & -3 & -1 & 20 & -57 & 0 & 7 & 0 & 38 & -131 & -3 \\
\hline U-236 & 0 & 0 & 1 & 0 & 0 & 0 & 0 & 2 & 0 & 0 & 0 & 0 & 1 & 0 & 0 \\
\hline U-238 & -1 & -1 & 72 & -12 & 2 & -1 & -1 & 54 & -7 & -1 & 0 & 0 & 40 & -1 & -4 \\
\hline $\mathrm{Cr}$ & 0 & 0 & 0 & 0 & -2 & 0 & 0 & 1 & 0 & -2 & 0 & 0 & 0 & 0 & -2 \\
\hline $\mathrm{Ni}$ & 0 & 0 & 1 & 0 & 1 & 0 & 0 & 1 & 0 & 0 & 0 & 0 & 0 & 0 & -1 \\
\hline $\mathrm{Fe}$ & 0 & 0 & -13 & 0 & -2 & 0 & 0 & -8 & 0 & -3 & 0 & 0 & -5 & 0 & -1 \\
\hline Mo & 0 & 0 & 1 & 0 & 0 & 0 & 0 & 1 & 0 & 0 & 0 & 0 & 0 & 0 & 0 \\
\hline Mm-55 & 0 & 0 & -1 & 0 & 1 & 0 & 0 & 0 & 0 & 1 & 0 & 0 & 0 & 0 & 0 \\
\hline $\mathrm{Zr}$ & 0 & 0 & -8 & 0 & 8 & 0 & 0 & -5 & 0 & 6 & 0 & 0 & -3 & 0 & 4 \\
\hline Sum over nuclides, pcm & -3 & -2 & 170 & -145 & 11 & -1 & -2 & 118 & -132 & 1 & 7 & -1 & 75 & -131 & -8 \\
\hline Leakage, pcm & \multicolumn{5}{|c|}{37} & \multicolumn{5}{|c|}{25} & \multicolumn{5}{|c|}{-140} \\
\hline$\delta \mathrm{k} / \mathrm{k}$ (estimated), pcm & \multicolumn{5}{|c|}{57} & \multicolumn{5}{|c|}{8} & \multicolumn{5}{|c|}{-190} \\
\hline$\delta \mathrm{k} / \mathrm{k}$ (calculated), pcm & \multicolumn{5}{|c|}{56} & \multicolumn{5}{|c|}{8} & \multicolumn{5}{|c|}{-191} \\
\hline $\begin{array}{l}\delta \mathrm{k} / \mathrm{k} \text { (estimated w/o } \\
\text { leakage error), } \mathrm{pcm}\end{array}$ & \multicolumn{5}{|c|}{19} & \multicolumn{5}{|c|}{-17} & \multicolumn{5}{|c|}{-51} \\
\hline Reflector thickness $(\mathrm{cm})$ & \multicolumn{5}{|c|}{16.1} & \multicolumn{5}{|c|}{12.8} & \multicolumn{5}{|c|}{8.8} \\
\hline
\end{tabular}

\footnotetext{
$*\left(\Sigma_{\mathrm{s}, \mathrm{TWODANT}}-\Sigma_{\mathrm{s}, \mathrm{VIM}}\right) \times 10^{5}\left[\mathrm{~cm}^{-1}\right]$
} 
The effects of isotopic cross section differences were examined by isolating the leakage effects. By using the leakage fractions determined from VIM calculations in the neutron balances of TWODANT calculations, the leakage errors of TWODANT calculations were arbitrarily eliminated. An additional reactivity deviation was estimated and included as " $\delta \mathrm{k} / \mathrm{k}$ (estimated w/o leakage error)" in Tables 2.10 and 2.11. The estimated reactivity values without leakage error are off from the reference VIM values by $23,39,2,19,-17$, and $-51 \mathrm{pcm} \Delta \rho$ for ZPPR-21A through $21 \mathrm{~F}$, respectively. These deviations are plotted in Figure 2.4 as a function of main isotope fractions in heavy metal. The estimated $\mathrm{k}_{\text {eff }}$ value with zero leakage error shows an increasing trend with increasing Pu-239 content, but a decreasing trend with increasing U-235 content. The magnitude of variation is small however, within $\pm 50 \mathrm{pcm}$, for a wide range of $\mathrm{Pu}$ 239 or U-235 fraction. In addition, in a mixture of Pu-239 and U-235, the errors tend to cancel each other. The situation is somewhat different for U-238. Although the range of U-238 fraction is rather narrow (from 37.3 to $47.5 \mathrm{w} / \mathrm{o}$ ), U-238 shows almost perfect correlation with the reactivity deviation; the correlation coefficient between reactivity deviation and U-238 fraction is about 0.99 . If this trend is extrapolated to a U-238 content of $80 \mathrm{w} / \mathrm{o}$ (as in typical power reactor) by neglecting the interaction effects among different nuclides, it is expected that $\mathrm{MC}^{2}-2$ /TWODANT would overestimate the core $\mathrm{k}_{\text {eff }}$ value by $290 \mathrm{pcm}$ relative to VIM.

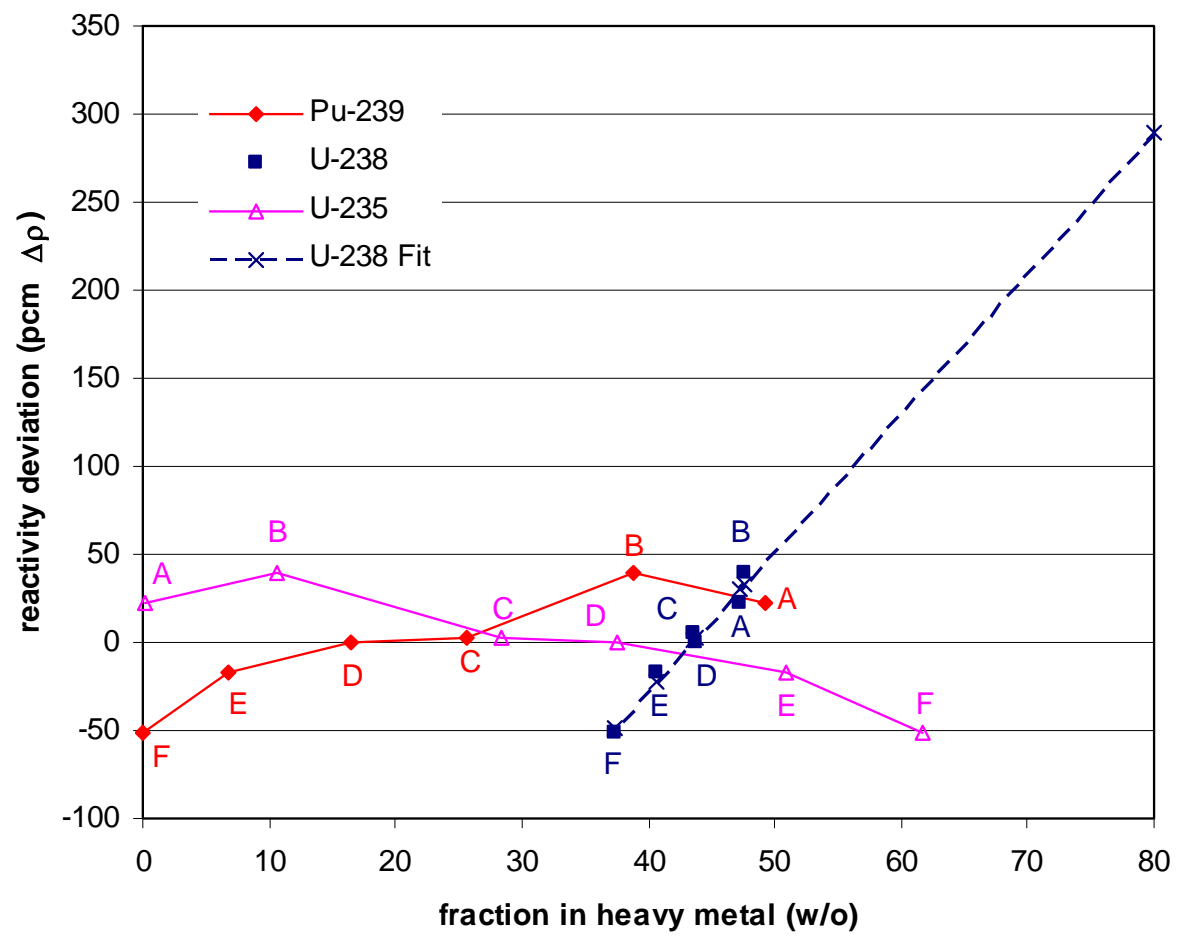

Figure 2.4 Deviation of TWODANT $k_{\text {eff }}$ Value Estimated with Zero Leakage Error from VIM $k_{\text {eff }}$ Value vs. Fraction of Main Nuclides in Heavy Metal 
The isotopic reaction results in Tables 2.10 and 2.11 show that the deterministic calculation with $\mathrm{MC}^{2}-2$ TWODANT underestimates both fission and capture reactions of most of the actinides relative to VIM. The underestimated capture and fission reactions respectively make positive and negative contributions to the reactivity. In the ZPPR-21 cores, the total contribution of capture reactions is in the range of 75 to $180 \mathrm{pcm}$, and the total contribution of fission reactions is in the range of -105 to $-142 \mathrm{pcm}$. These positive and negative contributions cancel each other, yielding a net contribution in the range of about -50 to $50 \mathrm{pcm}$.

In the ZPPR-21A core, where $\mathrm{Pu}-239$ is the main fissile isotope, the $\mathrm{Pu}-239$ contribution is $-36 \mathrm{pcm}$, and the contribution of all the $\mathrm{Pu}$ isotopes is almost zero. The $23 \mathrm{pcm}$ deviation from the VIM value mainly comes from the U-238 contribution. In ZPPR-21B, the Pu-239 content is reduced relative to ZPPR-21A, thus the Pu-239 contribution is reduced slightly to $-34 \mathrm{pcm}$. The total contribution of all the $\mathrm{Pu}$ isotopes increases to $18 \mathrm{pcm}$, most of which is due to reduced capture reactions. The total contribution of U-238 is $43 \mathrm{pcm}$, and this is the main contributor to the positive reactivity deviation from VIM, as in ZPPR-21A. In the case of ZPPR-21F where U235 is the only fissile nuclide, the negative reactivity deviation from VIM is mainly due to the underestimated U-235 fission. The results in Tables 2.10 and 2.11 also indicate that the resonance absorption of $\mathrm{Pu}-240$ and $\mathrm{U}-238$ are underestimated by $\mathrm{MC}^{2}-2 / \mathrm{TWODANT}$ relative to VIM.

In this study, resonance-like Fe cross sections above the resonance region were self-shielded using the SHIELD program. The difference in Fe scattering cross sections between TWODANT and VIM, as shown in Tables 2.10 and 2.11, indicates that Fe cross sections were properly selfshielded. The effects of this Fe cross section shielding were estimated to be 63, 73, 71, 70, 74, and $65 \mathrm{pcm}$ for ZPPR-21A through 21F, respectively.

\subsection{Validation of $\mathrm{MC}^{2}$-2/TWODANT against Benchmark Experimental Values}

Table 2.12 compares the TWODANT core $\mathrm{k}_{\text {eff }}$ results with benchmark values. For comparison purposes, VIM results are also included. TWODANT results were obtained from $\mathrm{P}_{5} \mathrm{~S}_{24}$ calculations with shielded $\mathrm{Fe}$ cross sections. The TWODANT $k_{\text {eff }}$ values are well within the 1-sigma measurement uncertainty, except for ZPPR-21B and 21C. For ZPPR-21B and 21C, the deviation is between the 1 and 2-sigma uncertainties. The mean and 1-sigma standard deviation of the differences between the TWODANT and benchmark $k_{\text {eff }}$ values for the six configurations are -20 and $230 \mathrm{pcm}$, respectively. As can be seen, TWODANT results are very consistent with VIM results. The correlation coefficients between the reactivity deviations and the heavy metal contents indicate that Pu-239 and U-238 contribute to overestimation of the core $\mathrm{k}_{\text {eff }}$ and U-235 contributes to underestimation.

Along with the verification results against VIM calculations discussed in Section 2.5, these results for the ZPPR-21 critical assemblies show that (1) the accuracy of the $M^{2}-2 /$ TWODANT system for core $\mathrm{k}_{\text {eff }}$ estimation is comparable to the VIM Monte Carlo code, and (2) the 
multigroup cross sections generated with $\mathrm{MC}^{2}-2$ accurately reproduce the isotopic reaction rates of VIM calculations.

Table 2.12 Comparison of TWODANT $k_{\text {eff }}$ Results with Benchmark Values

\begin{tabular}{|c|c|c|c|c|c|}
\hline & Benchmark & VIM & TWODANT & $\begin{array}{c}\text { VIM- } \\
\text { Benchmark, } \\
\text { pcm } \Delta \mathrm{k}\end{array}$ & $\begin{array}{c}\text { TWODANT- } \\
\text { Benchmark, } \\
\text { pcm } \Delta \mathrm{k}\end{array}$ \\
\hline $21 \mathrm{~A}$ & $0.9967 \pm 0.0026$ & $1.0000 \pm 0.0002$ & 0.99873 & 330 & 200 \\
\hline $21 \mathrm{~B}$ & $0.9897 \pm 0.0023$ & $0.9925 \pm 0.0002$ & 0.99293 & 280 & 320 \\
\hline $21 \mathrm{C}$ & $0.9998 \pm 0.0023$ & $0.9979 \pm 0.0002$ & 0.99698 & -190 & -280 \\
\hline $21 \mathrm{D}$ & $1.0018 \pm 0.0024$ & $0.9997 \pm 0.0002$ & 1.00042 & -210 & -140 \\
\hline $21 \mathrm{E}$ & $1.0012 \pm 0.0024$ & $1.0000 \pm 0.0002$ & 1.00008 & -120 & -110 \\
\hline $21 \mathrm{~F}$ & $0.9998 \pm 0.0025$ & $1.0005 \pm 0.0002$ & 0.99852 & 70 & -130 \\
\hline \multicolumn{4}{|c|}{ Mean \pm one standard deviation of $(\mathrm{C}-\mathrm{M}), \mathrm{pcm} \Delta \mathrm{k}$} & $30 \pm 240$ & $-20 \pm 230$ \\
\hline \multicolumn{4}{|c|}{ Correlation coefficient with $\mathrm{Pu}-239$} & 0.78 & 0.70 \\
\hline \multicolumn{4}{|c|}{ Correlation coefficient with U-238 } & 0.60 & 0.68 \\
\hline \multicolumn{4}{|c|}{ Correlation coefficient with U-235 } & -0.75 & -0.70 \\
\hline
\end{tabular}

\subsection{Group Collapsing Methods}

Although the 230-group $\mathrm{MC}^{2}-2 /$ TWODANT calculations produce accurate solutions comparable to VIM Monte Carlo results, the computational time required is typically too long to be practical for routine design calculations. As an attempt to devise a more efficient procedure for routine design calculations, therefore, several methods to collapse fine-group cross sections to broad-group cross sections were examined.

Direct generation of broad-group cross sections from $\mathrm{MC}^{2}-2$ calculations was first tested. For each composition in the core, 33-group cross sections were generated directly from $\mathrm{MC}^{2}-2$ calculations. Then, TWODANT calculations were performed using these 33-group cross sections. The resulting core $\mathrm{k}_{\mathrm{eff}}$ values are compared with 230-group solutions in Table 2.13. These values deviate from the 230-group solutions by $-423,-309,-353,-250,-264$, and $-376 \mathrm{pcm}$, respectively, for ZPPR-21 configurations A through F. Examination of reaction rates indicated that most of these deviations were due to the differences in the leakage rates, but in the case of ZPPR-21D, about $25 \%$ of the deviation was attributed to differences in production and absorption rates. These results suggest a need to use a group collapsing scheme as a standard method of generating broad-group cross sections.

Scalar flux weighting was tested first. All the 230-group cross sections were collapsed to region-wise 33-group cross sections using the scalar flux obtained from 230-group TWODANT calculations, and then TWODANT calculations were repeated with these 33-group cross sections. The resulting core $\mathrm{k}_{\mathrm{eff}}$ values are included in Table 2.13 as " $230 \mathrm{G} \Rightarrow 33 \mathrm{G}, \phi_{0}$-weighted." 
Compared to the reference 230-group solutions, the resulting 33-group solutions overestimate the core $\mathrm{k}_{\mathrm{eff}}$ value by $212,237,216,231,215$, and 195 pcm for ZPPR-21 configurations A through F, respectively. It was found that most of these deviations were attributed to reduced leakage out of the core region. In other words, the current out of the core was not preserved between 230-group and 33-group TWODANT calculations. This is due to the total flux weighting used for collapsing higher-order scattering cross sections.

Table 2.13 $\mathbf{k}_{\text {eff }}$ Results of ZPPR-21 Cores Obtained with Different Group Collapsing Methods

\begin{tabular}{|l|c|c|c|c|c|c|}
\hline \multicolumn{1}{|c|}{ Configuration } & $\mathrm{A}$ & $\mathrm{B}$ & $\mathrm{C}$ & $\mathrm{D}$ & $\mathrm{E}$ & $\mathrm{F}$ \\
\hline 230 Group, Consistent $\mathrm{P}_{5}$ & 0.99873 & 0.99293 & 0.99698 & 1.00042 & 1.00008 & 0.99852 \\
\hline 33 Group, Consistent $\mathrm{P}_{5}$ & 0.99453 & 0.98989 & 0.99348 & 0.99793 & 0.99745 & 0.99479 \\
\hline $\begin{array}{l}230 \mathrm{G} \Rightarrow 33 \mathrm{G}, \phi_{0} \text {-weighted, } \\
\text { Consistent } \mathrm{P}_{5}\end{array}$ & 1.00085 & 0.99530 & 0.99914 & 1.00274 & 1.00224 & 1.00047 \\
\hline $\begin{array}{l}\text { 230G } \Rightarrow 33 \mathrm{G},\left|\phi_{n, 0}\right| \text {-weighted, } \\
\text { Consistent } \mathrm{P}_{5}\end{array}$ & 0.99896 & 0.99303 & 0.99708 & 1.00036 & 1.00005 & 0.99859 \\
\hline $\begin{array}{l}\text { 230G } \Rightarrow 33 \mathrm{G}, \sum_{m}\left|\phi_{m, n}\right|- \\
\text { weighted, Consistent } \mathrm{P}_{5}\end{array}$ & 0.99901 & 0.99326 & 0.99721 & 1.00068 & 1.00025 & 0.99864 \\
\hline
\end{tabular}

In multigroup transport theory calculations, the scattering source of order $n$ from a group $g^{\prime}$ to a group $g$ in the direction $\Omega$ is represented as

$$
\sum_{m=-n}^{n} \sum_{g^{\prime} \rightarrow g}^{n} \phi_{n, m}^{g^{\prime}} Y_{n, m}(\Omega)
$$

where $\sum_{g^{\prime} \rightarrow g}^{n}$ is the $n$-th order scattering cross section, $\phi_{n, m}^{g^{\prime}}$ is the spherical harmonics moment of the angular flux of group $g^{\prime}$, and $Y_{n, m}(\Omega)$ is the spherical harmonic function evaluated at direction $\Omega$. To preserve the scattering source of order $n$ from a broad-group $G^{\prime}$ to a broadgroup $G$, the broad-group scattering cross section from $G^{\prime}$ to $G$ needs to be defined as

$$
\sum_{G^{\prime} \rightarrow G}^{n} \sum_{m=-n}^{n} \phi_{n, m}^{G^{\prime}} Y_{n, m}(\Omega)=\sum_{g \in G} \sum_{g^{\prime} \in G^{\prime}} \sum_{g^{\prime} \rightarrow g}^{n} \sum_{m=-n}^{n} \phi_{n, m}^{g^{\prime}} Y_{n, m}(\Omega) .
$$

Since the spherical harmonics are orthogonal to each other, this equation represents $2 n+1$ independent equations

$$
\sum_{G^{\prime} \rightarrow G}^{n} \phi_{n, m}^{G^{\prime}}=\sum_{g \in G} \sum_{g^{\prime} \in G^{\prime}} \sum_{g^{\prime} \rightarrow g}^{n} \phi_{n, m}^{g^{\prime}}, \quad-n \leq m \leq n .
$$

Thus higher-order scattering cross sections cannot be defined uniquely to preserve the scattering source for all directions. 
For collapsing higher-order scattering cross sections, two weighting spectra were tested. The first one was the spectrum of $\phi_{n, 0}$ as used in the cross section generation codes based on onedimensional unit cell transport calculations. This is equivalent to selecting a direction and preserving the higher-order scattering sources in this direction. However, the angular flux moments calculated from a fine-group transport calculation cannot be used directly as a weighting spectrum. The higher flux moments for a fixed direction may change their sign within a broad group at low energy. For example, at a core and reflector interface, the fine-group higher order moments are positive (i.e., directed toward the reflector) for the higher energy part of the broad group and negative (i.e., directed toward the core) for the lower energy part of the broad group. As a result, the summation of the fine-group flux moments in this broad group become very small or even negative, yielding unphysical broad-group scattering cross sections. Under the assumption that the flux moments are separable in energy and space within each broad group and a spatial region over which the group collapsing is to be done, the sign change of flux moments can be attributed to the spatial part, and then the energy part becomes positive. Therefore, the absolute value of $\phi_{n, 0}$ was used as the weighting spectrum. The TWODANT calculation results obtained using the region-dependent 33-group cross sections collapsed with $\left|\phi_{n, 0}\right|$ are included in Table 2.13 as " $230 \mathrm{G} \Rightarrow 33 \mathrm{G},\left|\phi_{n, 0}\right|$-weighted." As can be seen, the 33-group calculations almost reproduce the 230-group results; the deviations are only $23,10,10,-6,-3$, and $7 \mathrm{pcm}$ for ZPPR-21 A through F, respectively.

The second approach was to use the summation of the flux moments corresponding to each scattering order; that is, $\Sigma_{m=-n}^{n}\left|\phi_{n, m}\right|$ was used as the weighting spectrum. The TWODANT calculation results obtained using the region-dependent 33-group cross sections collapsed with this approach are included in Table 2.13 as " $230 \mathrm{G} \Rightarrow 33 \mathrm{G}, \Sigma_{m}\left|\phi_{m, n}\right|$-weighted." The results are essentially the same as those obtained with the $\left|\phi_{n, 0}\right|$ spectrum. These results suggest that either $\left|\phi_{n, 0}\right|$ or $\sum_{m=-n}^{n}\left|\phi_{n, m}\right|$ can be used for collapsing higher-order scattering cross sections. 


\section{Analysis of ZPPR-15 Phase A Loading 15, 16 and 20}

Three loading configurations of the ZPPR-15 Phase A experiments were analyzed. As-built Monte Carlo calculation models were developed using the reactor loading records and drawer master information. Based on these as-built core models, deterministic calculation models were developed by homogenizing each drawer. The reported calculation values constitute bases for comparison with experimental results for criticality and sodium void worth. Multigroup cross sections were generated using the ETOE-2/MC ${ }^{2}-2 / \mathrm{SDX}$ code system based on the ENDF/B-V.2 data. Core calculations were performed with the DIF3D nodal transport option [14] and VIM Monte Carlo code. The predicted multiplication factors were compared with the experimental values provided in the ZPPR-15 Monthly Progress Reports [15, 16].

\subsection{Description of ZPPR-15 Phase A Critical Experiments}

The IFR Benchmark Physics Test Program, also known as the ZPPR-15 program, was conducted in ANL's Zero Power Plutonium Reactor (ZPPR) facility from April 1985 through July 1986. The focus of the program was to provide experimental support for core designs using metallic alloy fuel. The basis for the critical assembly was a 330 MWe sodium-cooled fast reactor. This reference design had a two-zone, 2500-litre conventional core with a single row of radial blanket assemblies. For the critical assembly design, the reference core design was simplified from hexagonal to cylindrical boundaries, and the composition was modified just enough to allow a uniform inner core loading. Tests included diverse reactor physics measurements such as criticality, void worth, region-wise spectral indices, reaction rates, control rod worth, and reactivity coefficients.

The ZPPR-15 Program was conducted in four phases. Each phase was marked by a particular composition of the reference assembly, with the last three being representations of the three stages of the IFR fuel cycle. Phase A was a clean physics assembly containing only plutonium, depleted uranium, stainless steel and sodium without zirconium. The succeeding phases had zirconium added to the core composition, enabling the zirconium effect to be separated out. This report deals with the ZPPR-15 Phase A benchmarks for initial criticality configuration (loading 15), a reference configuration for sodium void worth measurement (loading 16), and a configuration with an 18 " sodium void in part of the inner core (loading 20).

\subsubsection{Core Layout of Reference Critical Loading}

In order to set up an as-built Monte Carlo VIM model that would serve as a reference solution for the deterministic calculations, the reactor loading records were retrieved to find the loading map, and then drawer master numbers were identified to establish the constituent loading materials within each master drawer. The as-built Monte Carlo model also provided 
homogenized region number densities over each unit cell for deterministic calculations and became a base model for plate heterogeneity effect evaluation.

Figure 3.1 shows a planar layout of the ZPPR-15 Loading Number 15 that is regarded as the reference critical configuration [15]. The ZPPR-15 assemblies are built from 55-mm square unit cells of varying axial length. In reality, stainless steel square tubes, of which the outside dimension is $55 \mathrm{~mm}$, were stacked and drawers containing core materials were placed within the tubes. The inner core consists of 448 unit cells, and the whole assembly layout in Figure 3.1 represents a total of 2,488 unit cells.

Figure 3.2 shows a schematic diagram for radial and axial arrangements. Each $55 \mathrm{~mm} \times 55$ $\mathrm{mm}$ unit cell extends axially up to $1.2 \mathrm{~m}$ from the mid-plane and is filled with various material zones representing the core, axial blanket and axial reflector. Total core volume is about 2,500 liters, split equally between inner and outer core. Beyond the axial blanket in each cell is a 12.7 $\mathrm{cm}$ long carbon steel block contained in the drawer. A $15.24 \mathrm{~cm}$ long stainless steel block was used to fill the end of the drawer.

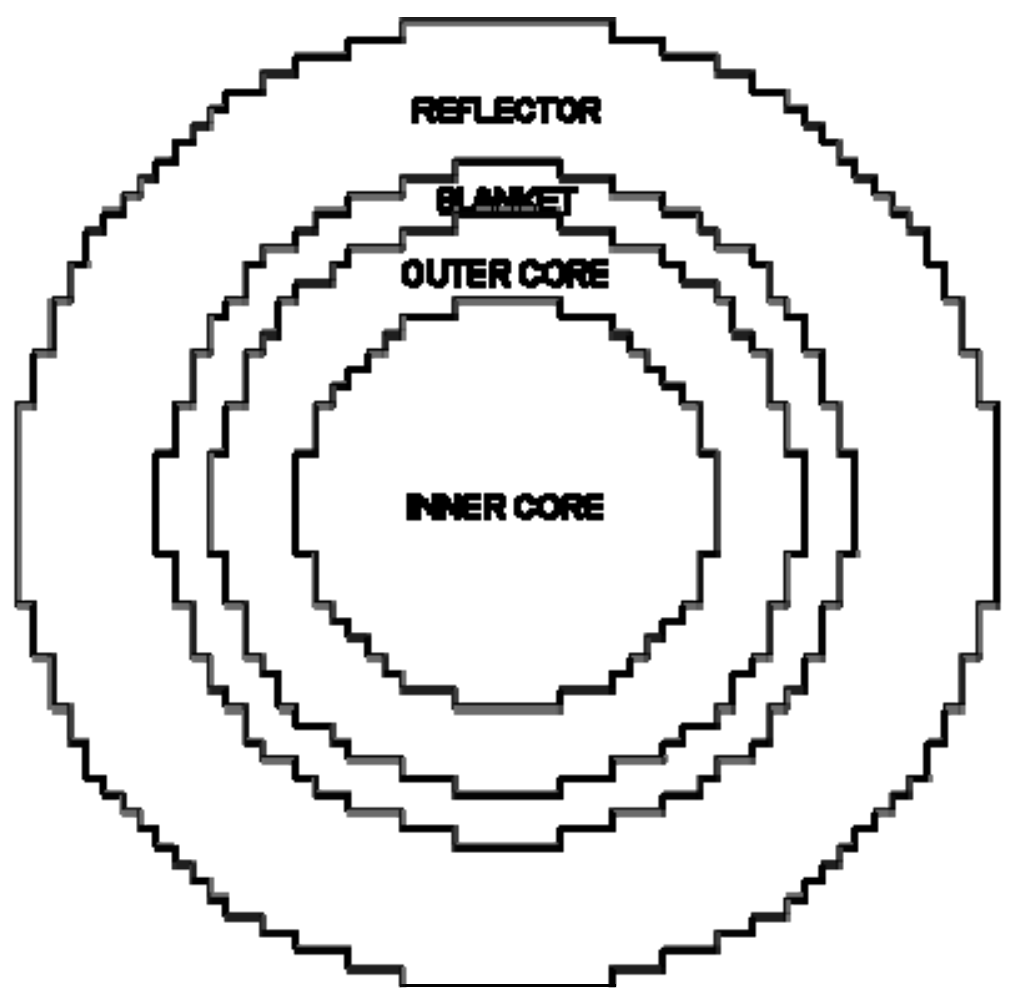

Figure 3.1. ZPPR-15 Loading 15 Reference Critical Planar Configuration 


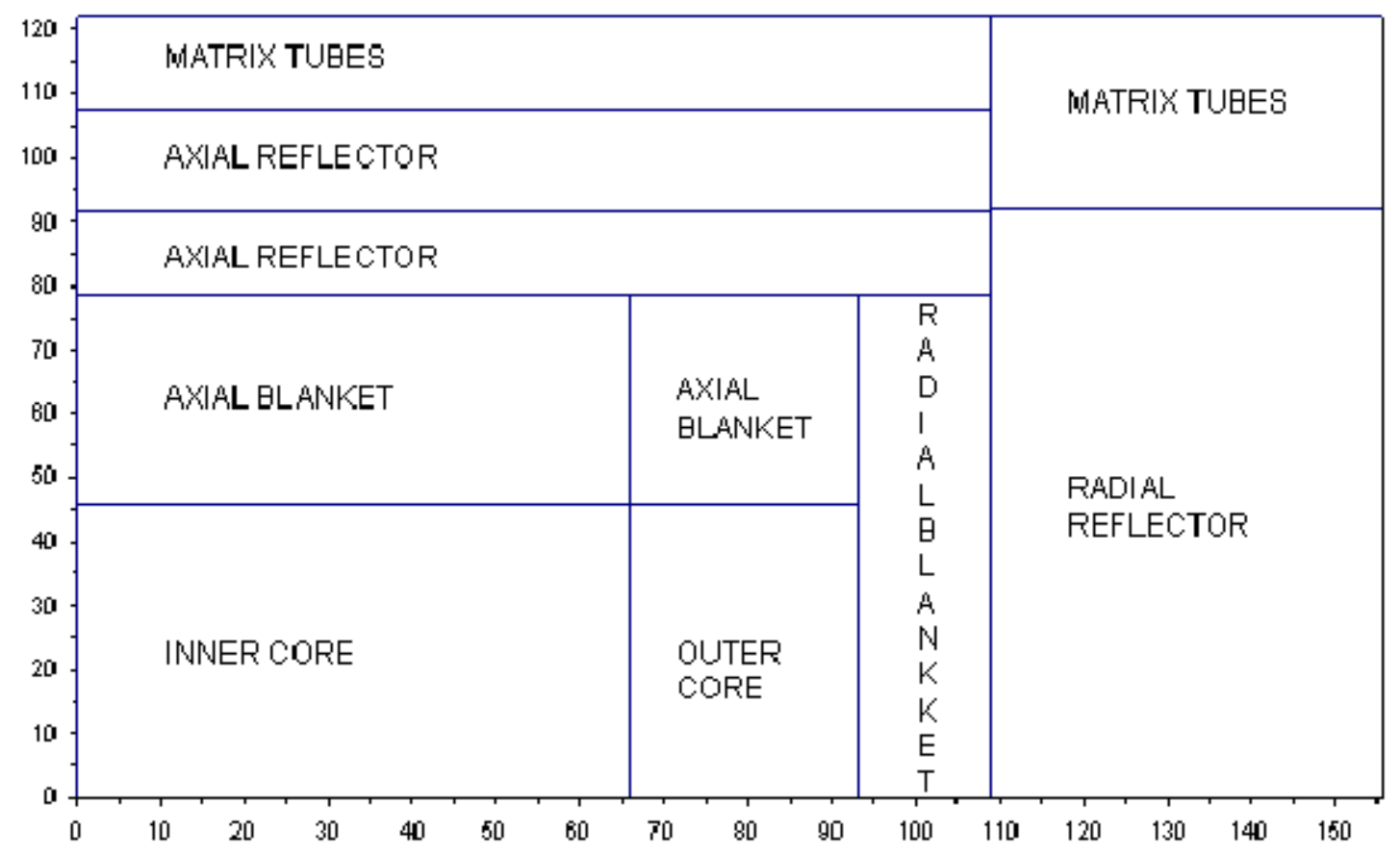

Figure 3.2 ZPPR-15 Loading 15 Reference Critical R-Z Dimensions [cm]

\subsubsection{Plate Geometry Description of Reference Critical Loading}

Square unit cells consist of the stainless-steel matrix tubes and drawers plus the constituent materials in plate form. Figure 3.3 shows a realistic model of the Master drawer 201 unit cell that is one of the master drawer types placed in the outer core region of ZPPR-15 Phase A. Note that each $\mathrm{Pu}-\mathrm{U}-\mathrm{Mo}$ fuel and sodium plate has cladding on the outside. The active core extends up to $45.80 \mathrm{~cm}$ from the mid-plane, but each distinctive material region does not necessarily consist of a single plate. In the case of $\mathrm{Pu}-\mathrm{U}-\mathrm{Mo}$ fuel, the region consists of three axially aligned plates, while the depleted $U$ region in the active core consists of two plates. In the as-built VIM model discussed below in Section 3.2, all the details as seen in this figure are included.

While a reference Monte Carlo model can incorporate all the details of each master drawer in a full three-dimensional configuration such as shown in Figure 3.3, deterministic calculations cannot afford such a detailed model due to the huge requirement for memory caused by refined meshes and material boundaries. It is currently impossible to apply a three-dimensional realistic model to a deterministic calculation. Accordingly, even in the heterogeneous model deterministic calculation for the generation of effective cross section sets, a reasonable degree of approximation of the geometric complexity had to be applied before homogenization. Figures 3.4 through 3.6 show schematic diagrams of each unit cell used in the current analysis for the 
deterministic heterogeneous calculation during the cross section processing. Figure 3.4 represents an inner core unit cell that is typical of the Pu single drawer. The double fuel columns in Figure 3.5 are representative of the fuel subassemblies loaded in the outer core region. In Figures 3.4 and 3.5, the axial blanket layout is also provided for the inner core and outer core. The axial blanket layout is identical in the inner core and outer core. The radial blanket configuration is shown in Figure 3.6. The arrangement of depleted uranium plates in the axial and radial blanket are different so as to correctly address directional leakage in each region. Although the geometry of each unit cell is simplified, the corresponding number densities are extracted in a judicious manner to preserve the heterogeneity effect. This is the topic of Section 3.3 for core plates and Section 3.4 for axial blanket plates.

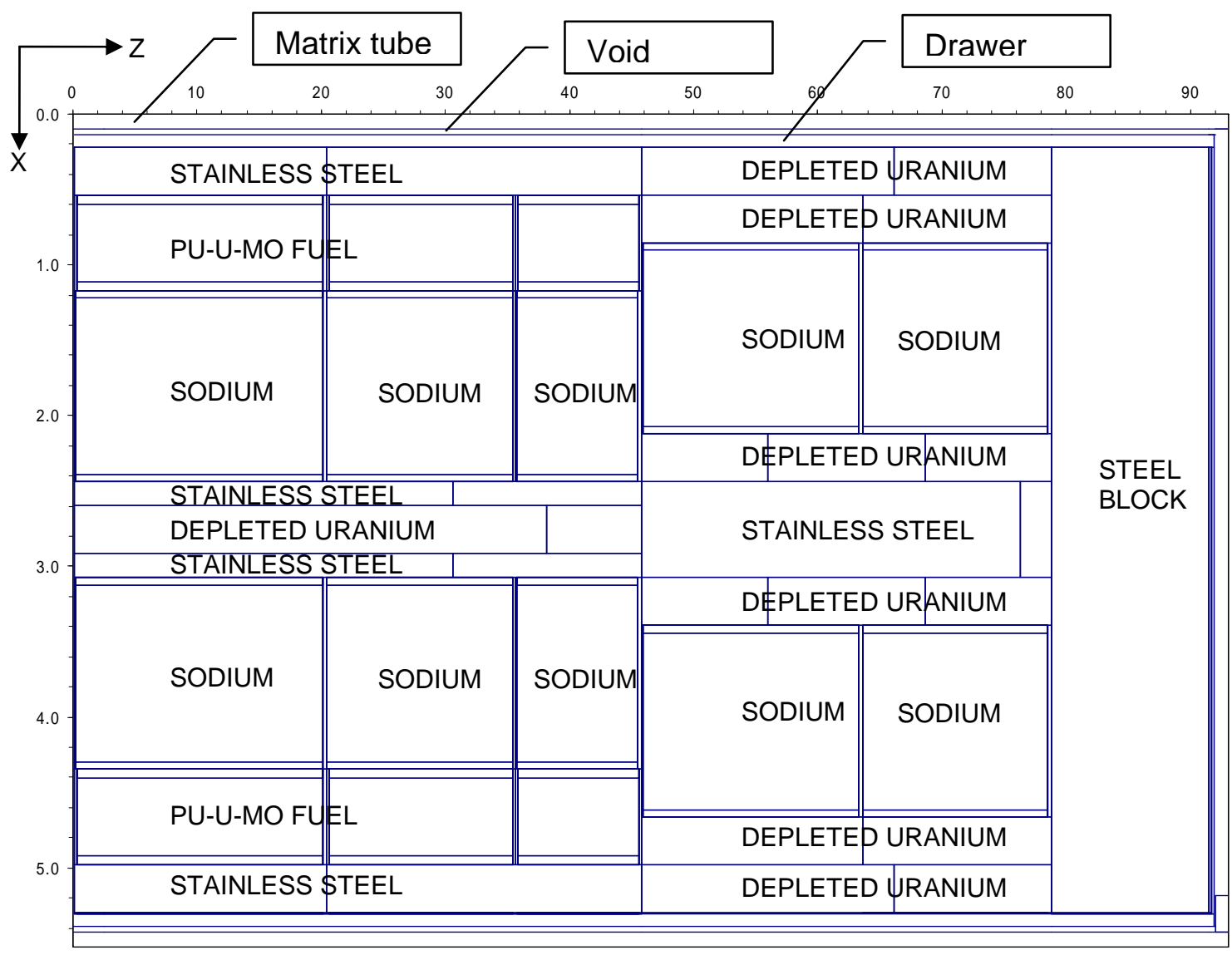

Figure 3.3 Realistic View (X-Z) of the Double-Fuel-Column Drawers (Master Drawer 201, Unit in cm) 


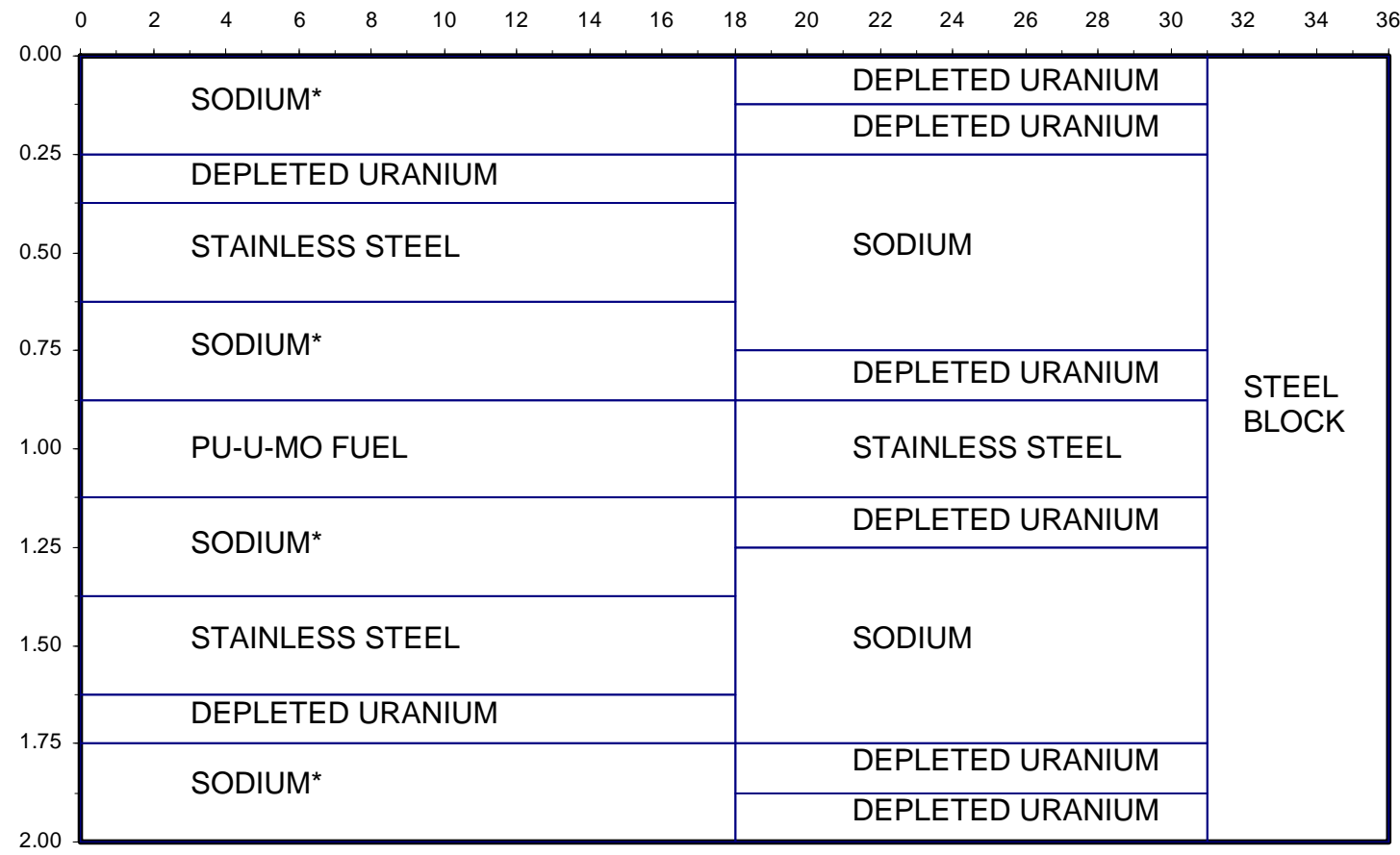

Figure 3.4 Plate Loading Pattern (X-Z) for Material in the Single-Fuel-Column Drawers

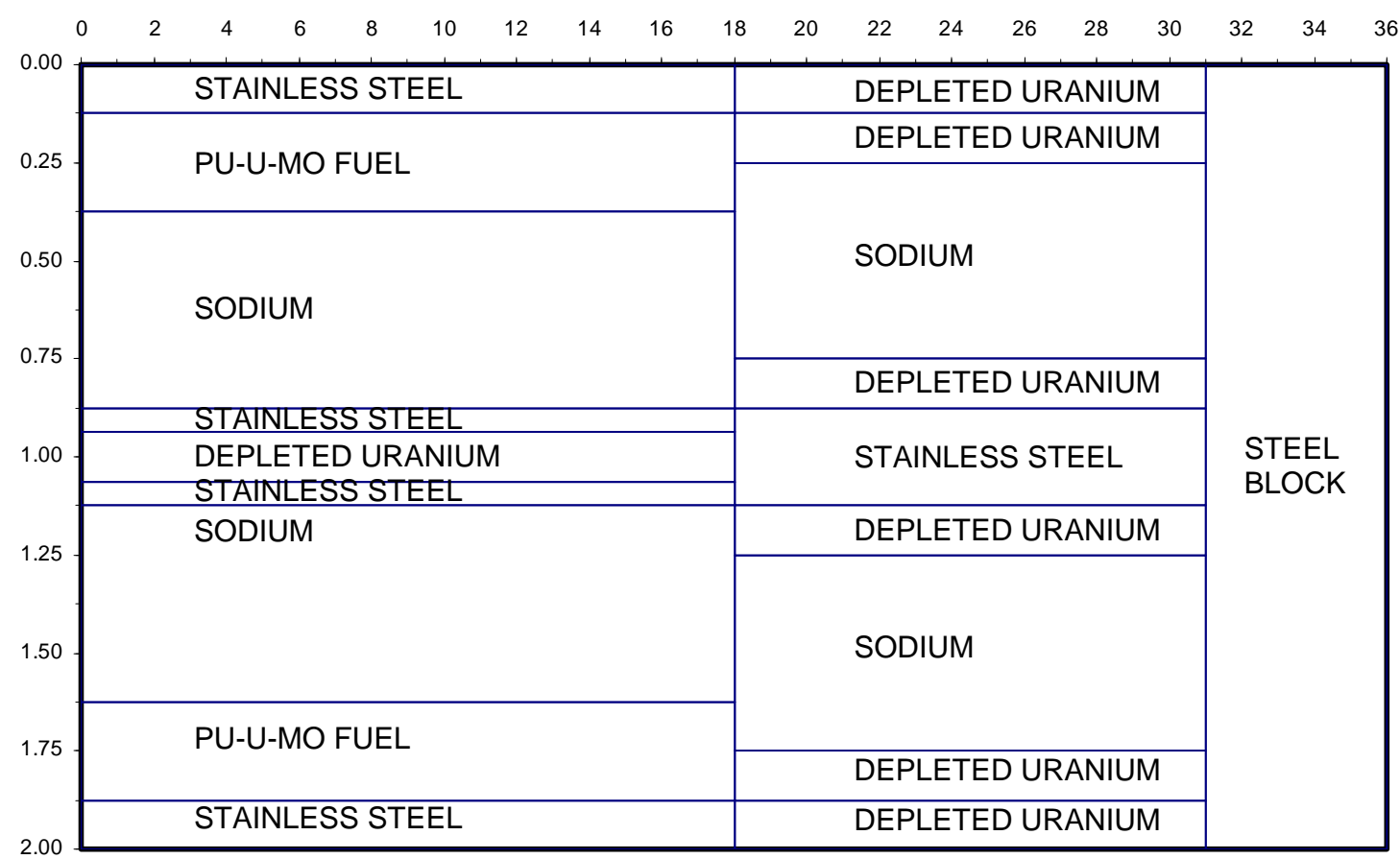

Figure 3.5 Plate Loading Pattern (X-Z) for Material in the Double-Fuel-Column Drawers 


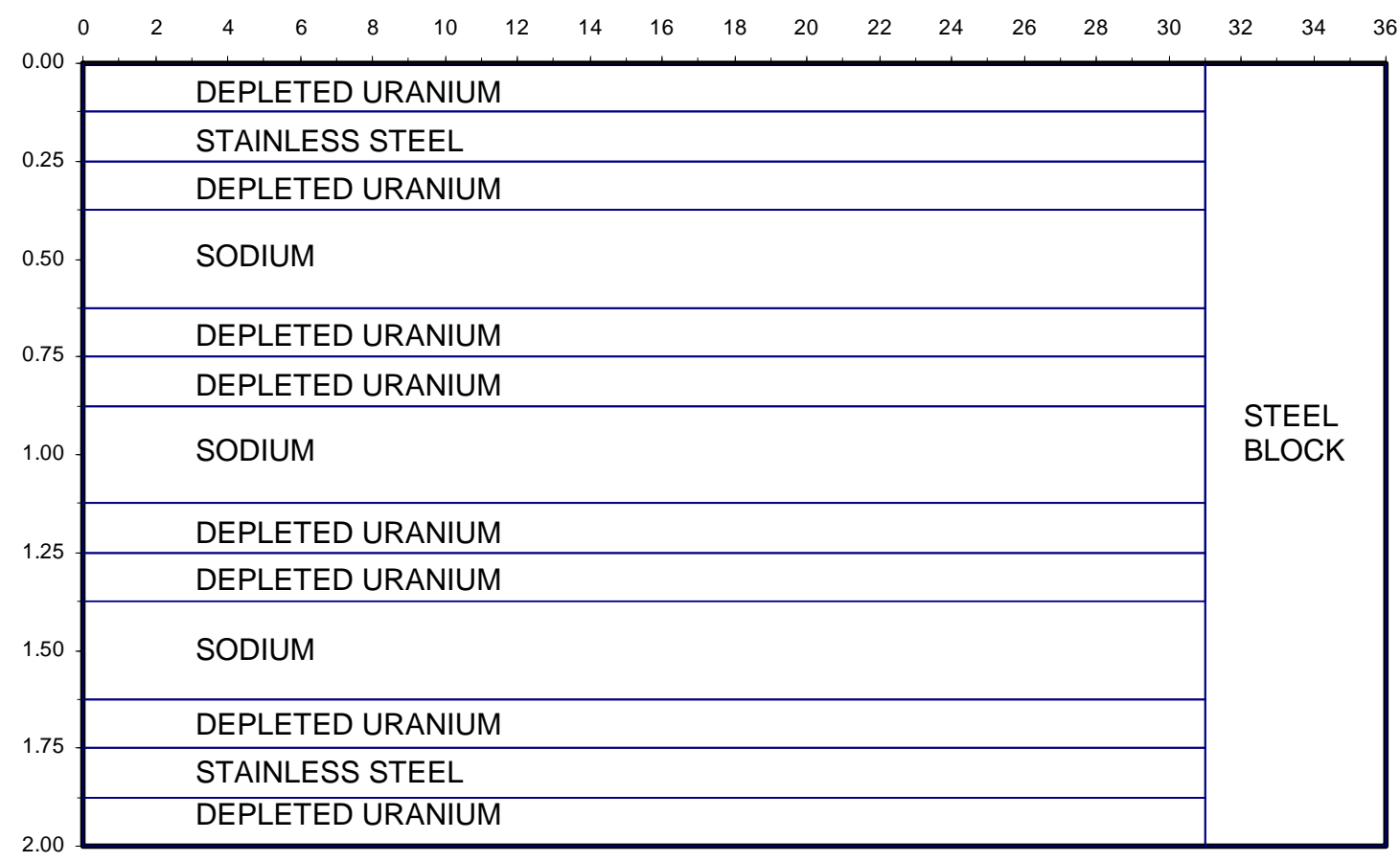

Figure 3.6 Plate Loading Pattern (X-Z) for Material in the Radial Blanket Drawers

\subsection{Monte Carlo Analysis of ZPPR-15 Reference Critical Loading 15}

A VIM Monte Carlo model was built for the ZPPR-15A Loading Number 15 configuration using as-built data found from the reactor loading records and drawer master information. This model provides homogenized region number densities for deterministic calculations as one of the outputs and becomes a base model for plate heterogeneity effect evaluation. Additional VIM calculations were performed with various core configurations and drawer models. Preliminary deterministic calculations were also performed, based on number densities reported in Reference 15. All the following calculations are based on ENDF-B/V.2 data.

Table 3.1 summarizes the core $\mathrm{k}_{\mathrm{eff}}$ results obtained with various computational models. The $\mathrm{k}_{\text {eff }}$ value of the experiment was determined by converting the measured excess reactivity of $0.134 \$[15]$. Since the evaluation of measurement uncertainty requires a significant effort, it was decided to use the maximum measurement uncertainty identified for the ZPPR-21 A through F assemblies as an estimated uncertainty of the ZPPR-15A experiment until a detailed measurement uncertainty evaluation is completed. As shown in Table 3.1, the VIM Monte Carlo solution of the full-core as-built model yielded a $430 \mathrm{pcm} \Delta \mathrm{k}$ underprediction in core $\mathrm{k}_{\text {eff }}$ from the measured value. This deviation is between two and three times the estimated measurement uncertainty. 
Table 3.1 $k_{\text {eff }}$ Results of ZPPR-15 Phase A Loading Number 15 Obtained with Various Computational Models

\begin{tabular}{|c|c|c|c|c|}
\hline \multicolumn{4}{|c|}{ Configuration } & ZPPR-15 A \\
\hline \multicolumn{4}{|c|}{ Experiment } & $1.00046 \pm \sim 0.0018$ \\
\hline Method & Core Layout & $\begin{array}{c}\text { Atomic } \\
\text { Densities }\end{array}$ & Drawer Model & Core $\mathrm{k}_{\mathrm{eff}}$ \\
\hline \multirow{2}{*}{ VIM Monte Carlo } & $\begin{array}{l}\text { Full-core } \\
\text { As-built }\end{array}$ & As-built & Heterogeneous & $0.99616 \pm 0.00010$ \\
\hline & $\begin{array}{l}\text { Octant-core } \\
\text { Monthly }\end{array}$ & As-built & Heterogeneous & $0.99647 \pm 0.00011$ \\
\hline \multirow{5}{*}{ VIM Monte Carlo } & $\begin{array}{c}\text { Full-core } \\
\text { As-built }\end{array}$ & As-built & Homogeneous & $0.98292 \pm 0.00011$ \\
\hline & $\begin{array}{c}\text { Quarter-core } \\
\text { As-built }\end{array}$ & As-built & Homogeneous & $0.98338 \pm 0.00011$ \\
\hline & $\begin{array}{c}\text { Octant-core } \\
\text { As-built }\end{array}$ & As-built & Homogeneous & $0.98329 \pm 0.00011$ \\
\hline & $\begin{array}{c}\text { Octant-core } \\
\text { Monthly }\end{array}$ & As-built & Homogeneous & $0.98321 \pm 0.00012$ \\
\hline & $\begin{array}{c}\text { Octant-core } \\
\text { Monthly }\end{array}$ & Monthly & Homogeneous & $0.98091 \pm 0.00010$ \\
\hline $\begin{array}{l}\text { DIF3D Nodal } \\
230-G, P_{5} S_{24} \\
\end{array}$ & $\begin{array}{c}\text { Octant-core } \\
\text { Monthly }\end{array}$ & Monthly & Homogeneous & 0.97989 \\
\hline $\begin{array}{c}\text { DIF3D Nodal } \\
\text { 230-G, Diffusion }\end{array}$ & $\begin{array}{c}\text { Octant-core } \\
\text { Monthly }\end{array}$ & Monthly & Homogeneous & 0.97698 \\
\hline
\end{tabular}

To develop more practical models for deterministic calculations, the symmetrical properties of the core were examined first. The ZPPR-15 Phase A Loading Number 15 was almost symmetrical with respect to the $x-y, y-z$, and z-x planes, but not perfectly symmetrical. The effect of the deviation from a perfectly symmetrical arrangement was investigated using the octant-core layout in a ZPPR Monthly Report [15] and the atomic densities and heterogeneous drawer configurations taken from the full-core as-built VIM model. This octant core model yielded a $\mathrm{k}_{\mathrm{eff}}$ value almost identical to that calculated by the full-core as-built model; the difference of $31 \mathrm{pcm}$ is within the $3 \sigma$ uncertainties of VIM Monte Carlo calculations. Therefore, it is justified to use a one-eighth core deterministic model for ZPPR-15 Loading Number 15 analysis.

To evaluate the gross effect of plate heterogeneity, a VIM Monte Carlo calculation was also performed with homogenized drawer configurations. The homogenized atomic densities of each drawer were determined from the VIM output of the full-core as-built model run. By comparing the VIM results for the two full-core models with heterogeneous and homogeneous drawer configurations, it can be seen that the plate heterogeneity effect is as large as $1324 \mathrm{pcm} \Delta \mathrm{k}$. This 
result strongly suggests that the cross section generation for deterministic calculations should be based on heterogeneous drawer models.

Using homogeneous drawer configurations, additional VIM calculations were done for various core layouts: full-core, quarter-core (above mid-plane), and octant-core layouts. As shown in Table 3.1, the difference in $\mathrm{k}_{\text {eff }}$ among these different core layouts is small (less than 50 $\mathrm{pcm}$ ). These results suggest that the octant-core model in the ZPPR Monthly Report is adequate for deterministic calculations to validate the deterministic design codes. However, the homogenized drawer atom densities reported in Reference 15 are slightly different from those derived from the VIM output for the full-core as-built model. The different atom densities resulted in a $230 \mathrm{pcm}$ difference in the VIM $\mathrm{k}_{\text {eff }}$ value. This is not a negligible difference, although this is from a statistical calculation. In addition, there is a strong desire to use plate-wise information to account for the plate heterogeneity effect. Unfortunately, this information is not available from the ZPPR-15 monthly report alone.

Deterministic calculations were performed using the octant-core model and homogenized drawer atom densities in Reference 15 . This is a quick process for a preliminary validity checkup of the deterministic design route, essentially accomplished by a comparison with the VIM Monte Carlo results. Using the $\mathrm{MC}^{2}-2$ code, effective microscopic cross sections were generated in a 230-group structure for the individual drawer master types reported in Reference 15 . For the 38 compositions specified, 18 different sets of cross sections were generated, considering the variation of atomic densities and the location in the core. For the compositions in the inner and outer core zones, a critical buckling calculation was used with the consistent $\mathrm{P}_{1}$ approximation. For the remaining compositions, a fixed-source calculation was done with a source spectrum derived from the leakage from the adjacent zone. As an example, the leakage spectrum from the core zone was used as a fixed source in the adjoining blanket region to obtain a new collapsing spectrum. The leakage spectrum derived from the blanket calculation was then used as a fixed source in the reflector. Higher-order scattering cross sections up to the fifth order were generated. The octant-core model for deterministic calculations was defined with 51 unique compositions by combining the 38 specified compositions and the 18 cross section sets. Nodal transport and diffusion calculations were performed using the DIF3D code [17], and the results are included in Table 3.1.

Compared to the VIM result $(0.98091 \pm 0.00011)$ for the octant-core model with homogenized drawer atom densities from Reference 15, the DIF3D-nodal transport solution obtained with $\mathrm{P}_{5}$ scattering order and $\mathrm{S}_{24}$ angular approximation underestimates the core $\mathrm{k}_{\mathrm{eff}}$ by only $102 \mathrm{pcm}$. This result suggests that the cross section generation scheme based on $\mathrm{MC}^{2}-2$ calculations handles the energy group effect and transport effect appropriately. The nodal diffusion solution underestimates the core $\mathrm{k}_{\mathrm{eff}}$ by 291 pcm relative to the nodal transport solution; in other words, the transport effect is $\sim 300 \mathrm{pcm}$. 


\subsection{Deterministic Model for Core Plate Heterogeneity Effects}

By comparing the VIM results for two full-core models with heterogeneous and homogeneous drawer configurations, the plate heterogeneity effect was determined to be 1324 $\mathrm{pcm}$. The heterogeneity of the ZPPR-15 plates is three-dimensional, but the cross section generation codes $\mathrm{MC}^{2}-2$ and SDX allow only one-dimensional unit cells. Therefore, a representative one-dimensional (1-D) model needed to be developed for multigroup cross section generation.

In search of an appropriate one-dimensional heterogeneous drawer model, several 1-D models were made from the active core zones of reference as-built subassembly models. Based on VIM calculations, the simplified 1-D models were tested against the as-built threedimensional model. The three main models are as follows:

Model 1: A one-dimensional heterogeneous model of each drawer was made along the drawer width (say, X-direction) perpendicular to the plate surfaces. The thickness of each distinctive material region was represented as it is, except for the small gap between drawer and matrix tube, which was homogenized with the drawer and matrix tube into a single material region. The Y- and Z-directional heterogeneities were removed by eliminating the gaps between plates and drawer and by extending each material region to fill the entire distance between top and bottom matrix tubes in the Y-direction and the entire drawer length in the Z-direction. The number density of each material was modified such that the each material mass in the drawer is preserved. The structural materials (matrix tube, drawer, and claddings of sodium and Pu-U-Mo plates) in the Y- and Z-directions were uniformly distributed into sodium and stainless steel plates, sodium and $\mathrm{Pu}-\mathrm{U}-\mathrm{Mo}$ plate claddings, drawer, and matrix tube. The structural material was not added to the Pu-U-Mo and depleted uranium plates to avoid increased background cross section impact on resonance selfshielding.

Model 2: A one-dimensional heterogeneous model was made along the X-direction using the plate number densities at the drawer mid-height without considering the Y-and Z-directional heterogeneities. As in Model 1, the small gap between drawer and matrix tube was homogenized with the drawer and matrix tube into a single material region. It is noted that this model contains more heavy metals than the actual 3-D model.

Model 3: This model is the same as Model 1, except that the number densities at the drawer mid-height are used for the heavy metal plates.

Using these 1-D models, the k-infinity values of master drawer 103 (inner core driver fuels) and master drawer 201 (outer core driver fuels) were calculated with the VIM Monte Carlo code. The resulting k-infinity values are compared in Table 3.2 with the reference values obtained with the as-built 3-D models. The heterogeneity effect of each 1-D model was estimated by comparing to the corresponding zero-dimensional homogeneous model. It is noted that the 1-D 
models have the same geometrical configuration but different material densities. As expected, none of the 1-D models could reproduce the heterogeneity effect of the as-built 3-D model (1849 $\mathrm{pcm} \Delta \mathrm{k}$ for the inner core unit cell and $1239 \mathrm{pcm} \Delta \mathrm{k}$ for the outer core unit cell). However, Model 1, which preserves the mass of each material in the drawer, yields the closest result to the actual 3-D heterogeneity effect. The heterogeneity effect determined with Model 1 is lower by $207 \mathrm{pcm} \Delta \mathrm{k}$ for the inner core unit cell and by $297 \mathrm{pcm} \Delta \mathrm{k}$ for the outer core unit cell.

Table 3.2 Core Region $k_{\infty}$ Values of ZPPR-15 Master Drawers 103 and 201 Obtained with Various Computational Models

\begin{tabular}{|c|c|c|c|c|c|}
\hline & & VIM $k_{\infty}$ & $\begin{array}{l}\text { Heterogeneity } \\
\text { effect, pcm } \Delta \mathrm{k}\end{array}$ & SDX & TWODANT* \\
\hline \multicolumn{6}{|c|}{ Master Drawer 103 (Representative Inner Core Unit Cell) } \\
\hline Reference & $3-\mathrm{D}$ & $1.18127 \pm 0.00015$ & 1849 & & \\
\hline \multirow{2}{*}{ Model 1} & $1-\mathrm{D}$ & $1.17912 \pm 0.00015$ & 1642 & 1.17734 & 1.17734 \\
\hline & $0-\mathrm{D}$ & $1.16270 \pm 0.00012$ & - & 1.16096 & 1.16096 \\
\hline \multirow{2}{*}{ Model 2} & $1-\mathrm{D}$ & $1.25050 \pm 0.00013$ & 1528 & 1.24975 & 1.17671 \\
\hline & $0-\mathrm{D}$ & $1.23522 \pm 0.00016$ & - & 1.23416 & 1.16197 \\
\hline \multirow{2}{*}{ Model 3} & $1-\mathrm{D}$ & $1.23998 \pm 0.00013$ & 1598 & 1.23902 & 1.17744 \\
\hline & $0-\mathrm{D}$ & $1.22400 \pm 0.00018$ & - & 1.22287 & 1.16194 \\
\hline \multicolumn{6}{|c|}{ Master Drawer 201 (Representative Outer Core Unit Cell) } \\
\hline Reference & $3-\mathrm{D}$ & $1.66201 \pm 0.00014$ & 1239 & & \\
\hline \multirow{2}{*}{ Model 1} & $1-\mathrm{D}$ & $1.65904 \pm 0.00013$ & 942 & 1.65845 & 1.65845 \\
\hline & $0-\mathrm{D}$ & $1.64962 \pm 0.00020$ & - & 1.64883 & 1.64883 \\
\hline \multirow{2}{*}{ Model 2} & $1-\mathrm{D}$ & $1.73175 \pm 0.00013$ & 818 & 1.73098 & 1.65765 \\
\hline & $0-\mathrm{D}$ & $1.72357 \pm 0.00010$ & - & 1.72298 & 1.64906 \\
\hline \multirow{2}{*}{ Model 3} & 1-D & $1.71521 \pm 0.00013$ & 852 & 1.71472 & 1.65857 \\
\hline & $0-\mathrm{D}$ & $1.70669 \pm 0.00011$ & - & 1.70588 & 1.64922 \\
\hline
\end{tabular}

*) TWODANT calculations were performed using the volume-averaged number densities (as in Model 1) and the effective homogenized cross sections obtained from the corresponding case.

For each of the above 1-D models, the effective homogenized cross sections were generated using the $\mathrm{MC}^{2}-2 / \mathrm{SDX}$ code system. In the $\mathrm{MC}^{2}-2 / \mathrm{SDX}$ calculation, the modules of $\mathrm{MC}^{2}-2$ generate the intermediate-group cross sections for individual regions, and the module CALHET calculates the heterogeneous flux distribution using these plate cross sections. The module SEF1D generates the effective broad-group homogenized cross sections for each unit cell using the heterogeneous flux distribution. In the current study, the intermediate-group cross sections were generated in the ANL 230-group structure, and the broad-group homogeneous cross sections were also generated in the same group structure without group collapsing. For comparison, the cross sections were also calculated using the zero-dimensional homogeneous models. 
Using the effective homogenized cross sections of the 1-D and 0-D models generated with $\mathrm{MC}^{2}$-2/SDX, TWODANT calculations were performed for a homogeneous model for which number densities were determined so as to preserve each material mass in the drawer, as in Model 1. The resulting k-infinity values are shown in Table 3.2 along with the values obtained from the $\mathrm{MC}^{2}-2 / \mathrm{SDX}$ calculations for cross section generation.

As can be seen, the k-infinity value of each 1-D or 0-D model obtained from an $\mathrm{MC}^{2}-2 / \mathrm{SDX}$ calculation agrees well with the corresponding VIM Monte Carlo result, within $200 \mathrm{pcm} \Delta \mathrm{k}$ for the inner core unit cell and $100 \mathrm{pcm} \Delta \mathrm{k}$ for the outer core unit cell. The heterogeneity effect of each 1-D model determined with an $\mathrm{MC}^{2}-2 / \mathrm{SDX}$ calculation shows even better agreement with the VIM result, within $40 \mathrm{pcm} \Delta \mathrm{k}$ for both inner and outer unit cells. The TWODANT k-infinity values obtained with the effective homogenized cross sections generated with 1-D MC ${ }^{2}-2 / \mathrm{SDX}$ calculations also agree well with the VIM result for the 1-D model with the same material densities (Model 1). These results indicate that the $\mathrm{MC}^{2}-2 / \mathrm{SDX}$ scheme is adequate for effective homogenized cross section generation. In addition, the TWODANT results show that the kinfinity value of the homogenized unit cell is relatively insensitive to the material number densities used in effective homogenized cross section generation.

It was decided to adopt Model 1 in $\mathrm{MC}^{2}-2 / \mathrm{SDX}$ calculations for generating the effective cross sections for other unit cells in ZPPR-15, including blanket and reflector regions.

\subsection{Deterministic Model for Blanket Plate Heterogeneity Effects}

In the 1-D heterogeneous model development for $\mathrm{MC}^{2}-2 / \mathrm{SDX}$ calculations, each drawer was modeled along the drawer width (say, X-direction) perpendicular to the plate surfaces. The thickness of each distinctive material region was represented as it is, except for the small gap between drawer and matrix tube, which was homogenized with the drawer and matrix tube into a single material region. The Y- and Z-directional heterogeneities were removed by eliminating the gaps between plates and drawer and by extending each material region to fill the entire distance between top and bottom matrix tubes in the Y-direction and the entire drawer length in the Zdirection. The number density of each material was modified such that each material mass in the drawer is preserved. The structural materials (matrix tube, drawer, and claddings of sodium and $\mathrm{Pu}-\mathrm{U}-\mathrm{Mo}$ plates) in the Y- and Z-directions were uniformly distributed into sodium and stainless steel plates, sodium and $\mathrm{Pu}-\mathrm{U}-\mathrm{Mo}$ plate claddings, drawer, and matrix tube. The structural material was not added to the $\mathrm{Pu}-\mathrm{U}-\mathrm{Mo}$ and depleted uranium plates to avoid increased background cross section impact on resonance self-shielding.

To investigate the heterogeneity effects of axial and radial blankets, the axial blanket of master drawer 201 (outer core region) and master drawer 501 (radial blanket) were analyzed with various models. The results of VIM and $\mathrm{MC}^{2}-2 / \mathrm{SDX}$ calculations are shown in Table 3.3 for master drawer 201 and in Table 3.4 for a 1-D core model including the radial blanket. In the VIM calculations for master drawer 201, the 3-D as-built model was used for the active core region, 
but the model for the axial blanket region was changed from the 3-D as-built model to a homogenized model. The 1-D core and axial blanket models were developed as described above. No incoming neutron boundary condition was imposed at the end of the axial blanket, while a reflective boundary condition was used at the core mid-plane. In the VIM calculations, the actual arrangement was modeled by placing the axial blanket plates on top of the active core plates. However, in the one-dimensional $\mathrm{MC}^{2}-2 / \mathrm{SDX}$ calculations, the axial blanket plates had to be placed next to the active core plates in parallel, although this arrangement cannot represent the neutron streaming in the direction parallel to blanket plates. The heterogeneity effects of the radial blanket were studied using a 1-D core model from the core center to the radial blanket. In this case, the neutrons are crossing multiple fuel plates to reach the radial blanket, and thus the streaming effect in the direction parallel to the fuel plates would be negligible.

Table 3.3 $\mathbf{k}_{\infty}$ Results of ZPPR-15 Master Drawers 201 for Different Axial Blanket Models

\begin{tabular}{|c|c|c|c|c|c|}
\hline $\begin{array}{l}\text { Core } \\
\text { Model }\end{array}$ & $\begin{array}{c}\text { Axial Blanket } \\
\text { Model }\end{array}$ & VIM $k_{\text {eff }}$ & $\begin{array}{l}\text { Heterogeneity } \\
\text { effect, pcm } \Delta \mathrm{k}\end{array}$ & SDX $\mathrm{k}_{\mathrm{eff}}$ & $\begin{array}{l}\text { Heterogeneity } \\
\text { effect, pcm } \Delta \mathrm{k}\end{array}$ \\
\hline 3-D & 3-D & $1.44705 \pm 0.00014$ & -250 & & \\
\hline $3-\mathrm{D}$ & 1-D & $1.44728 \pm 0.00021$ & -227 & & \\
\hline $3-\mathrm{D}$ & Homogenized & $1.44955 \pm 0.00015$ & - & & \\
\hline None* & Homogenized & $0.25189 \pm 0.00009$ & & & \\
\hline $1-\mathrm{D}$ & $1-\mathrm{D}$ & & & 1.44929 & 23 \\
\hline $1-\mathrm{D}$ & Homogenized & & & 1.44906 & - \\
\hline None* & $1-\mathrm{D}$ & & & 0.25583 & 304 \\
\hline None* & Homogenized & & & 0.25279 & - \\
\hline
\end{tabular}

${ }^{*}$ Axial blanket model with reflective boundary conditions.

Table 3.4 Heterogeneity Effect of ZPPR-15 Master Drawers 501 (Radial Blanket) Obtained with Various Computational Models

\begin{tabular}{|c|c|c|c|c|}
\hline $\begin{array}{c}\text { Inner Core } \\
\text { Model }\end{array}$ & $\begin{array}{c}\text { Outer Core } \\
\text { Model }\end{array}$ & $\begin{array}{c}\text { Radial Blanket } \\
\text { Model }\end{array}$ & VIM kff $_{\text {eff }}$ & $\begin{array}{c}\text { Heterogeneity } \\
\text { effect, pcm } \Delta \mathrm{k}\end{array}$ \\
\hline 1-D & 1-D & $1-\mathrm{D}$ & $1.21208 \pm 0.00011$ & 1410 \\
\hline 1-D & $1-\mathrm{D}$ & Homogenized & $1.21191 \pm 0.00011$ & 1393 \\
\hline Homogenized & Homogenized & Homogenized & $1.19798 \pm 0.00012$ & - \\
\hline
\end{tabular}

The VIM results for master drawer 201 obtained with 3D and homogenized models of the axial blanket show that the heterogeneity effect of the axial blanket is negative $(-250 \mathrm{pcm} \Delta \mathrm{k})$. This result indicates that the decrease in leakage due to homogenization overwhelms the increase in resonance absorption. In fact, the $\mathrm{MC}^{2}-2 / \mathrm{SDX}$ results for the 1-D and homogenized models of the axial blanket itself with reflective boundary conditions show that homogenization of the axial blanket reduces the resonance absorption and thus yields a positive heterogeneity effect (304 pcm $\Delta \mathrm{k})$. As mentioned before, in the one-dimensional $\mathrm{MC}^{2}-2 / \mathrm{SDX}$ calculations, the axial 
blanket plates had to be placed next to the active core plates in parallel, and hence the axial leakage in the direction parallel to the blanket plates is not properly represented. As a result, for the 1-D axial blanket model, the $\mathrm{MC}^{2}-2 / \mathrm{SDX}$ result is higher by $\sim 200 \mathrm{pcm} \Delta \mathrm{k}$ than the VIM solution, because of underestimated axial leakage. When the axial blanket is homogenized, the SDX result is very close to the VIM solution (only $49 \mathrm{pcm} \Delta \mathrm{k}$ higher), as expected. Thus, the heterogeneity effect of the axial blanket estimated from $\mathrm{MC}^{2}-2 / \mathrm{SDX}$ calculations is $\sim 270 \mathrm{pcm} \Delta \mathrm{k}$ higher than that estimated from VIM calculations with the actual geometrical arrangement. This result suggests that the use of the $\mathrm{MC}^{2}-2 / \mathrm{SDX}$ procedure might not be appropriate to treat the heterogeneity effect of the axial blanket.

It is noted that the heterogeneity effect of the axial blanket $(-250 \mathrm{pcm} \Delta \mathrm{k})$ is much smaller than that of the outer core unit cell $(\sim 1200 \mathrm{pcm} \Delta \mathrm{k})$. Furthermore, since the neutron importance is much smaller in the axial blanket than in the active core, this heterogeneity effect estimated for an infinite array of axial blankets would be reduced significantly in the whole core problem. The VIM results in Table 3.4 obtained with a 1-D core model from the core center to the radial blanket also show that the heterogeneity effect of the radial blanket is negligible. While the core heterogeneity effect is $1393 \mathrm{pcm} \Delta \mathrm{k}$, the radial blanket heterogeneity effect is only an additional $17 \mathrm{pcm} \Delta \mathrm{k}$. Therefore, it was decided to neglect the heterogeneity effects of axial and radial blankets and to use the $\mathrm{MC}^{2}-2$ procedure for generating the cross sections of axial and radial blankets. Specifically, the axial and radial blanket cross sections are generated for homogenized compositions by solving the slowing down equation with a fixed source, which is determined from the leakage spectrum from the adjacent core region. The $\mathrm{MC}^{2}-2 / \mathrm{SDX}$ procedure to account for the heterogeneity effect is applied only to the active core regions.

\subsection{Sodium Void Worth Comparison}

In order to evaluate sodium void worth, octant core analyses were performed for two loadings of ZPPR-15A (Loading 16 and 20). The nodal $\mathrm{S}_{\mathrm{N}}$ transport and nodal diffusion options of the DIF3D code were used with an octant core model based on as-built number densities. As discussed in Section 3.2, the octant-core model in a ZPPR Monthly Report [15] and the atomic densities and heterogeneous drawer configurations taken from the full-core as-built VIM model yielded almost identical $k_{\text {eff }}$ values. This is the ZPPR-15A critical reference configuration established in Loading Number 15. To measure a sodium void worth, Loading Number 15 was gradually converted to Loading Number 20. In Loading Number 16, eight double-fuel-column drawers in the outer core region were replaced with single-fuel-column drawers (inner core fuel) to reduce core $\mathrm{k}_{\text {eff }}$ before sodium voiding. After successive replacement of less voided drawers with more voided drawers, Loading Number 20 achieved an 18 inch axial voiding in each half core for a part of the inner core region (regions originally occupied by master drawers 101 and 103 of Loading Number 15). 
The octant-core DIF3D model was made of 55 different regions. Using $\mathrm{MC}^{2}-2 / \mathrm{SDX}$ for the active core region or $\mathrm{MC}^{2}-2$ procedures alone for regions outside of the active core, 230-group cross sections were generated for 31 different compositions. The radial node size was $5.5245 \mathrm{~cm}$, and the axial mesh size was approximately $5 \mathrm{~cm}$. The octant core model was represented by $33 \times 33 \times 26$ nodes just for modeling the $1 / 4$ quadrant of upper core. The $\mathrm{k}_{\text {eff }}$ results of ZPPR-15A Loadings 15,16 , and 20 obtained with different solution options and core models are provided in Tables 3.5 through 3.7. In these tables, the "Octant-core" layout denotes the core model where the detector drawer is explicitly modeled, and the "Octant-core Monthly" layout denotes the core model where this special drawer is represented by one of the inner core drawers (Drawer Master 103 ) as in the ZPPR Monthly Report. As mentioned above, the VIM results in Table 3.5 for the "Full-core As-built" and "Octant-core Monthly" models for ZPPR-15A Loading 15 show a small difference of $31 \mathrm{pcm} \Delta \mathrm{k}$ in $\mathrm{k}_{\mathrm{eff}}$. Based on this result, Loadings 16 and 20 were analyzed using octant-core models.

Tables 3.5 through 3.7 show that the VIM Monte Carlo solutions consistently underestimate the experimental $\mathrm{k}_{\mathrm{eff}}$ values; $430 \mathrm{pcm} \Delta \mathrm{k}$ for Loading 15, $427 \mathrm{pcm} \Delta \mathrm{k}$ for Loading 16, and 324 pcm $\Delta \mathrm{k}$ for Loading 20. As can be seen, however, the DIF3D nodal transport solutions obtained with the 230-group cross sections generated with the $\mathrm{MC}^{2}-2 / \mathrm{SDX}$ code system agree very well with the VIM Monte Carlo results. The DIF3D solutions underestimate the $\mathrm{k}_{\mathrm{eff}}$ value by only 122 , 106 , and $101 \mathrm{pcm} \Delta \mathrm{k}$ for Loadings 15,16 , and 18 , respectively.

Table $3.5 \mathbf{k}_{\text {eff }}$ Results of ZPPR-15 Loading 15

\begin{tabular}{|c|c|c|c|c|}
\hline \multicolumn{3}{|c|}{ Configuration } & ZPPR-15 A Loading 15 \\
\hline \multicolumn{3}{|c|}{ Experiment } & $1.00046 \pm \sim 0.0018$ \\
\hline \multirow{2}{*}{ Method } & Layout & No. Density & Sub-Assembly & $\mathrm{k}_{\text {eff }}$ \\
\hline $\begin{array}{c}\text { VIM } \\
\text { Monte Carlo } \\
\text { Full-core } \\
\text { As-built }\end{array}$ & $\begin{array}{c}\text { Octant-core } \\
\text { Monthly }\end{array}$ & As-built & Heterogeneous & $0.99616 \pm 0.00010$ \\
\cline { 2 - 5 } & $\begin{array}{c}\text { Octant-core } \\
\text { Monthly }\end{array}$ & As-built & Homogenized & $0.98321 \pm 0.00012$ \\
\hline $\begin{array}{c}\text { DIF3D Nodal } \\
\text { 230-G S }\end{array}$ & $\begin{array}{c}\text { Octant-core } \\
\text { Monthly }\end{array}$ & As-built & Heterogeneous & 0.99525 \\
\hline $\begin{array}{c}\text { DIF3D Nodal } \\
\text { 230-G Diffusion }\end{array}$ & $\begin{array}{c}\text { Octant-core } \\
\text { Monthly }\end{array}$ & As-built & Heterogeneous & 0.99263 \\
\hline $\begin{array}{c}\text { DIF3D Nodal } \\
\text { 230-G S }\end{array}$ & $\begin{array}{c}\text { Octant-core } \\
\text { Monthly }\end{array}$ & As-built & Homogenized & 0.98286 \\
\hline
\end{tabular}


Table $3.6 \mathbf{k}_{\text {eff }}$ Results of ZPPR-15 Loading 16

\begin{tabular}{|c|c|c|c|c|}
\hline \multicolumn{4}{|c|}{ Configuration } & ZPPR-15 A Loading 16 \\
\hline \multicolumn{4}{|c|}{ Experiment } & $0.99627 \pm \sim 0.0018$ \\
\hline Method & Layout & No. Density & Sub-Assembly & $\mathrm{k}_{\text {eff }}$ \\
\hline $\begin{array}{c}\text { VIM } \\
\text { Monte Carlo }\end{array}$ & $\begin{array}{l}\text { Octant-core } \\
\text { Monthly }\end{array}$ & As-built & Heterogeneous & $0.99200 \pm 0.00013$ \\
\hline $\begin{array}{c}\text { DIF3D Nodal } \\
230-G \mathrm{~S}_{24} \\
\end{array}$ & $\begin{array}{c}\text { Octant-core } \\
\text { Monthly }\end{array}$ & As-built & Heterogeneous & 0.99094 \\
\hline $\begin{array}{c}\text { DIF3D Nodal } \\
230-G S_{24}\end{array}$ & Octant-core & As-built & Heterogeneous & 0.99104 \\
\hline $\begin{array}{c}\text { DIF3D Nodal } \\
230-G_{24} \\
\end{array}$ & Octant-core & As-built & Homogenized & 0.97862 \\
\hline
\end{tabular}

Table $3.7 \mathbf{k}_{\text {eff }}$ Results of ZPPR-15 Loading 20

\begin{tabular}{|c|c|c|c|c|}
\hline \multicolumn{4}{|c|}{ Configuration } & ZPPR-15 A Loading 20 \\
\hline \multicolumn{4}{|c|}{ Experiment } & $0.99853 \pm \sim 0.0018$ \\
\hline Method & Layout & No. Density & Sub-Assembly & $\mathrm{k}_{\mathrm{eff}}$ \\
\hline $\begin{array}{c}\text { VIM } \\
\text { Monte Carlo }\end{array}$ & Octant-core & As-built & Heterogeneous & $0.99529 \pm 0.00012$ \\
\hline $\begin{array}{c}\text { DIF3D Nodal } \\
230-\mathrm{G} \mathrm{S}_{24}\end{array}$ & Octant-core & As-built & Heterogeneous & 0.99428 \\
\hline $\begin{array}{l}\text { DIF3D Nodal } \\
230-\mathrm{G} \mathrm{S}_{24}\end{array}$ & Octant-core & As-built & Homogenized & 0.98275 \\
\hline
\end{tabular}

The heterogeneity effects and sodium void worth are summarized in Tables 3.8 and 3.9. The plate heterogeneity effects estimated by the $\mathrm{MC}^{2}-2 / \mathrm{SDX}$ procedure represent the heterogeneity effects of the active core only. In the case of Loading 15, the heterogeneity effect of the active core estimated with the $\mathrm{MC}^{2}-2 / \mathrm{SDX}$ procedure is $1239 \mathrm{pcm} \Delta \mathrm{k}$, while the total heterogeneity effect (including the blanket heterogeneity effects) estimated with VIM calculations is $1326 \mathrm{pcm}$ $\Delta \mathrm{k}$. Considering that the actual 3D heterogeneity effect cannot be recovered by 1-D unit cell models completely (see Section 3.3), this result indicates that the blanket heterogeneity effect is much smaller than the active core heterogeneity effect and that the $\mathrm{MC}^{2}-2 / \mathrm{SDX}$ procedure represents the overall heterogeneity effect adequately. Note that the heterogeneity effect is smaller in Loading 20 by $\sim 120 \mathrm{pcm} \Delta \mathrm{k}$ than in Loading 15 and Loading 16 . As expected, the hardened spectrum due to sodium voiding reduces the resonance self-shielding and thus the heterogeneity effect. 
Table 3.8 Comparison of Heterogeneity Effects

\begin{tabular}{|c|c|c|c|c|}
\hline Method & Layout & No. Density & Loading No. & $\begin{array}{c}\text { Heterogeneity Effect } \\
(\mathrm{pcm} \Delta \mathrm{k})\end{array}$ \\
\hline $\begin{array}{c}\text { VIM } \\
\text { Monte Carlo }\end{array}$ & Octant-core & As-built & L15 & 1326 \\
\hline $\begin{array}{c}\text { DIF3D Nodal } \\
\text { 230-G S }\end{array}$ & Octant-core & As-built & L15 & 1239 \\
\hline $\begin{array}{c}\text { DIF3D Nodal } \\
\text { 230-G S } 24\end{array}$ & Octant-core & As-built & L16 & 1242 \\
\hline $\begin{array}{c}\text { DIF3D Nodal } \\
\text { 230-G S }\end{array}$ & Octant-core & As-built & L20 & 1123 \\
\hline
\end{tabular}

Table 3.9 Comparison of Sodium Void Worth

\begin{tabular}{|c|c|c|c|c|}
\hline & & & & Void Worth (pcm $\Delta \mathrm{k})$ \\
\hline \multicolumn{4}{|c|}{ Experiment } & 226 \\
\hline Method & Layout & No. Density & Sub-Assembly & \\
\hline $\begin{array}{c}\text { VIM } \\
\text { Monte Carlo }\end{array}$ & Octant-core & As-built & Heterogeneous & 319 \\
\hline $\begin{array}{c}\text { DIF3D Nodal } \\
230-\mathrm{G} \mathrm{S}_{24} \\
\end{array}$ & Octant-core & As-built & Heterogeneous & 324 \\
\hline $\begin{array}{l}\text { DIF3D Nodal } \\
230-\mathrm{G} \mathrm{S}_{24}\end{array}$ & Octant-core & As-built & Homogenized & 413 \\
\hline
\end{tabular}

The results in Table 3.9 show that the sodium void worth estimated from DIF3D nodal transport calculations agrees very well with the VIM result. Note that the sodium void worth is significantly overestimated when the homogenized drawers are used in generating cross sections. This is due to the reduced heterogeneity effect in the sodium voided case, where the hardened spectrum due to sodium voiding reduces the resonance self-shielding. The results in Table 3.9 also show that the calculated sodium void worth is noticeably larger than the measured value. This is considered to be due to the approximate modeling of void drawers in Loading 20. While Loading 15 and Loading 16 were modeled with as-built data, the void drawers of Loading 20 were modeled by simply removing sodium plates from the pre-existing master drawers. In the asbuilt Loading 20, however, master drawers 101 and 102 were replaced with master drawers 111, 112,114 , and 811 . Further investigation is needed to identify the reason for the discrepancy between calculated and measured sodium void worths.

Another possible cause of discrepancy between the prediction and the measurement may arise from the mismatch between the as-built full core and the octant core representation. The 
number of fission detector subassemblies in both Loading Number 16 and Loading Number 20 were noted to be placed by $1,1,2$, and 1 for $1 / 4,2 / 4,3 / 4$, and $4 / 4$ quadrants, respectively. The significance of this loading is that drawers containing fission chambers and the drawers opposite those containing fission chambers were not voided while narrow drawers adjacent to PSR rods were voided. Subassembly placement can be seen in Figure 3.7 for Loading Number 20 where the section highlighted in yellow was voided for 18 inches, extending from the core mid-plane, except for the detector subassemblies.

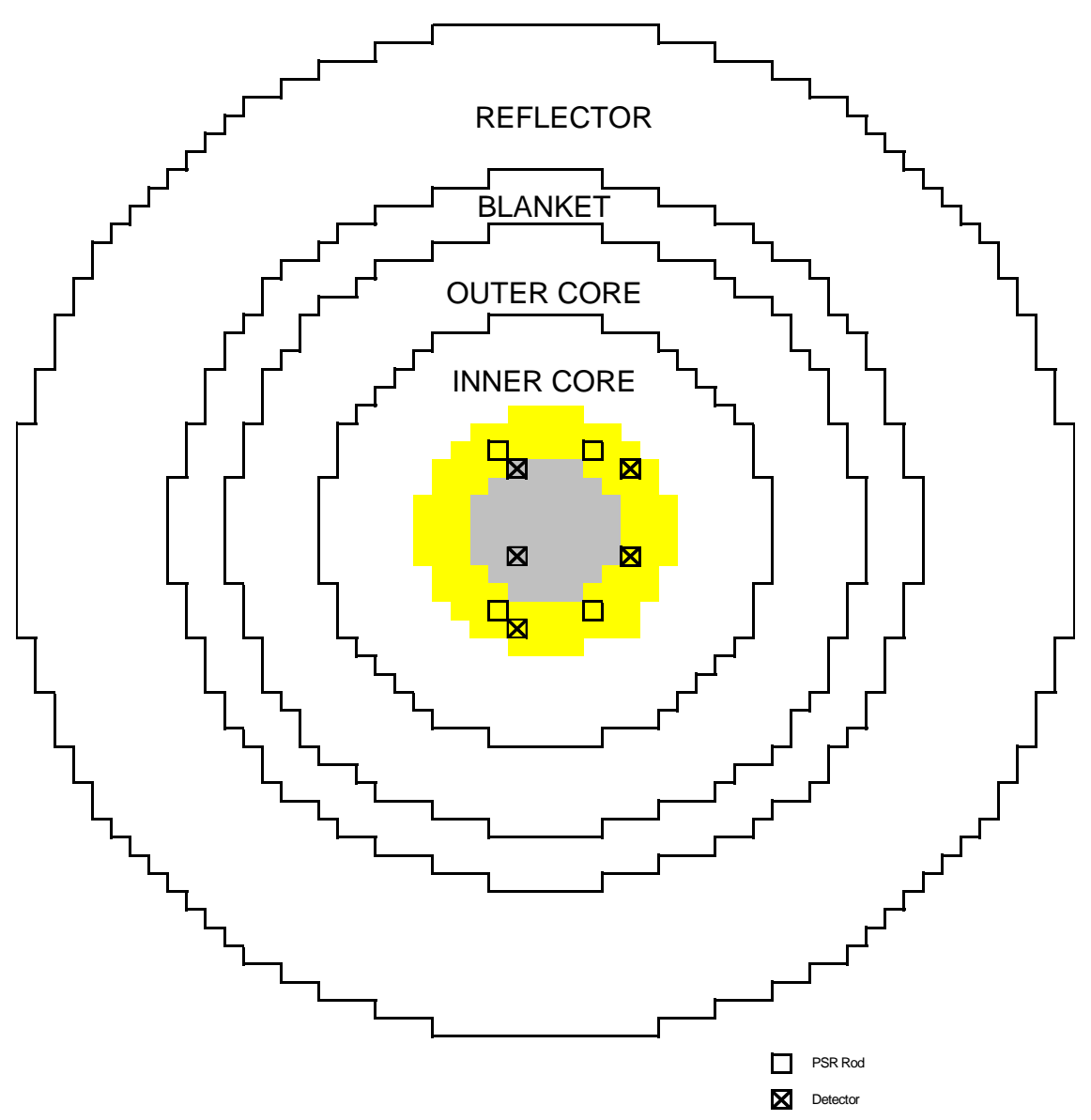

Figure 3.7 Core Layout for Loading Number 20

Table 3.10 compares the core $\mathrm{k}_{\text {eff }}$ values for the octant- and full-core configuration that serve as the reference configuration for the sodium void worth comparison. The results are almost identical, and it is to be expected that the fission detector assembly itself would be almost identical to the regular inner core subassemblies.

Table 3.11 shows comparisons between octant- and full-core calculation results for Loading Number 20, where asymmetric voiding occurs in each quadrant of the full core model. The 
results are still almost identical. This result demonstrates how deliberately Loading Number 20 was built to minimize the effect of different detector positions and numbers of detectors in each quadrant. Another point is that the asymmetric detector positioning does not influence the value of the sodium void worth predicted either by the VIM Monte Carlo or the DIF3D nodal transport method. Further investigation is worthwhile to identify the reason for the discrepancy between calculated and measured sodium void worths.

Table 3.10 Comparison of ZPPR-15 Loading $16 \mathbf{k}_{\mathrm{eff}}$ Results

\begin{tabular}{|c|c|c|c|c|}
\hline \multicolumn{3}{|c|}{ Configuration } & ZPPR-15 A Loading 16 \\
\hline \multicolumn{3}{|c|}{ Experiment } & $0.99627 \pm \sim 0.0018$ \\
\hline Method & Layout & No. Density & Sub-Assembly & $\mathrm{k}_{\text {eff }}$ \\
\hline $\begin{array}{c}\text { DIF3D Nodal } \\
\text { 230-G S } 24\end{array}$ & Octant-core & As-built & Heterogeneous & 0.99104 \\
\hline $\begin{array}{c}\text { DIF3D Nodal } \\
\text { 230-G S }\end{array}$ & Full-core & As-built & Heterogeneous & 0.99106 \\
\hline
\end{tabular}

Table 3.11 Comparison of ZPPR-15 Loading $20 \mathbf{k}_{\text {eff }}$ Results

\begin{tabular}{|c|c|c|c|c|}
\hline \multicolumn{4}{|c|}{ Configuration } & ZPPR-15 A Loading 20 \\
\hline \multicolumn{3}{|c|}{ Experiment } & $0.99853 \pm \sim 0.0018$ \\
\hline Method & Layout & No. Density & Sub-Assembly & $\mathrm{k}_{\text {eff }}$ \\
\hline $\begin{array}{c}\text { VIM } \\
\text { Monte Carlo }\end{array}$ & Octant-core & As-built & Heterogeneous & $0.99529 \pm 0.00012$ \\
\hline $\begin{array}{c}\text { VIM } \\
\text { Monte Carlo }\end{array}$ & Full-core & As-built & Heterogeneous & $0.99499 \pm 0.00012$ \\
\hline $\begin{array}{c}\text { DIF3D Nodal } \\
\text { 230-G S }\end{array}$ & Octant-core & As-built & Heterogeneous & 0.99428 \\
\hline $\begin{array}{c}\text { DIF3D Nodal } \\
\text { 230-G S }\end{array}$ & Full-core & As-built & Heterogeneous & 0.99426 \\
\hline
\end{tabular}

In summary, the $\mathrm{MC}^{2}-2 / \mathrm{SDX}$ procedure for multigroup cross section generation appears to represent the plate heterogeneity accurately. In this procedure, the active core drawers were modeled as 1-D slab unit cells by preserving each material mass, and the blanket heterogeneity was neglected. With the effective cross sections of every distinct unit cell generated in this procedure, the whole-core DIF3D nodal transport calculations yielded accurate $\mathrm{k}_{\text {eff }}$ values. The DIF3D solutions for three loadings of ZPPR-15A are only about $100 \mathrm{pcm} \Delta \mathrm{k}$ smaller than the 
VIM Monte Carlo results for 3-D heterogeneous models. Although the possibility of error cancellation cannot be excluded, these results suggest that the $\mathrm{MC}^{2}-2 / \mathrm{SDX}$ procedure is adequate for generating effective cross sections of heterogeneous unit cells.

It was shown that the VIM Monte Carlo solutions consistently underestimate the experimental $\mathrm{k}_{\text {eff }}$ values; $430 \mathrm{pcm} \Delta \mathrm{k}$ for Loading 15, $427 \mathrm{pcm} \Delta \mathrm{k}$ for Loading 16, and $324 \mathrm{pcm}$ $\Delta \mathrm{k}$ for Loading 20. However, the DIF3D nodal transport solutions obtained with the 230-group cross sections generated with the $\mathrm{MC}^{2}-2 / \mathrm{SDX}$ code system agree very well with the VIM Monte Carlo results. The DIF3D solutions underestimate the $\mathrm{k}_{\text {eff }}$ value by only 122,106 , and $101 \mathrm{pcm}$ $\Delta \mathrm{k}$ for Loadings 15,16 , and 20 , respectively.

In case of Loading 15 , the heterogeneity effect of the active core estimated with the $\mathrm{MC}^{2}$ 2/SDX procedure is $1239 \mathrm{pcm} \Delta \mathrm{k}$, while the total heterogeneity effect (including the blanket heterogeneity effects) estimated with VIM calculations is $1326 \mathrm{pcm} \Delta \mathrm{k}$. Considering that the actual 3D heterogeneity effect cannot be recovered by 1-D unit cell models completely, this result indicates that the blanket heterogeneity effect is much smaller than the active core heterogeneity effect and that the $\mathrm{MC}^{2}-2 / \mathrm{SDX}$ procedure represents the overall heterogeneity effect adequately. 


\section{Conclusions}

A study was performed to validate the existing tools for fast reactor neutronics analysis against previous critical experiments. The six benchmark problems for the ZPPR-21 critical experiments phases A through F specified in the Handbook of Evaluated Criticality Safety Benchmark Experiments were analyzed. The benchmark models were developed based on the VIM analyses for the as-built core models that represented all the experimental details, and specified the region-averaged compositions, region volumes, and the global RZ geometry. Analysis was also performed for three loading configurations of the ZPPR-15 Phase A experiments. As-built core models were developed in XYZ geometries using the reactor loading records and drawer master information. Deterministic calculation models were developed by homogenizing each drawer and by accounting for the plate heterogeneities in the generation of effective multigroup cross sections.

Detailed Monte Carlo and deterministic transport calculations were performed, along with various modeling sensitivity analyses. The Monte Carlo simulations were carried out with the VIM code with continuous energy cross sections based on the ENDF/B-V.2 data. For deterministic calculations, region-dependent 230-group cross sections were generated using the ETOE-2/MC ${ }^{2}-2 / \mathrm{SDX}$ code system, again based on the ENDF/B-V.2 data. Plate heterogeneity effects were taken into account by SDX unit cell calculations. Core calculations were performed with the TWODANT discrete ordinate code for the ZPPR-21 benchmarks, and with the DIF3D nodal transport option for the ZPPR-15 experiments.

For all six ZPPR-21 configurations where the Pu-239 concentration varies from 0 to 49 w/o and the U-235 concentration accordingly varies from 62 to $0 \mathrm{w} / \mathrm{o}$, the core multiplication factor determined with a 230-group TWODANT calculation agreed with the VIM Monte Carlo solution within $0.20 \% \Delta \mathrm{k}$, and there was no indication of any systematic bias. The quality of principal

cross sections generated with the $\mathrm{MC}^{2}-2$ code was comparable to that of VIM cross sections. The overall reactivity effect due to the errors in the 230-group principal cross sections was estimated to be less than $0.05 \% \Delta \mathrm{k}$. The statistics of the differences between calculated values and specified benchmark experimental values showed similar bias (from $-0.28 \% \Delta \mathrm{k}$ to $0.33 \% \Delta \mathrm{k}$ ) for $M^{2}-2 / T W O D A N T$ and VIM. This result suggests that the criticality prediction accuracy of $\mathrm{MC}^{2}-2 /$ TWODANT is comparable to VIM.

The neutron leakage fraction of the ZPPR-21 cores was very large, in the range from $51 \%$ to $60 \%$. As a result, the transport effect was as large as $10 \% \Delta \mathrm{k}$, and at least $\mathrm{P}_{3}$ anisotropic scattering order was required. Investigation of group collapsing methods showed that direct generation of broad-group cross sections from $\mathrm{MC}^{2}-2$ calculations was not adequate for analysis of ZPPR-21 assemblies. Scalar flux weighting for all cross sections, including anisotropic cross sections, was not sufficiently accurate, either. The use of higher flux moments for anisotropic scattering cross section collapsing reproduced the fine-group results with broad-group calculations. 
The ZPPR-15 analyses, starting from detailed as-built plate geometries, showed that the plate heterogeneity effect was as large as $1.3 \% \Delta \mathrm{k}$. This result strongly suggested that the cross section generation for deterministic calculations should be based on heterogeneous drawer models. Through a series of sensitivity studies, a procedure to generate effective cross sections was developed based on one-dimensional SDX unit cell calculations. With this procedure to account for the plate heterogeneity effect, the core multiplication factor determined with a 230-group DIF3D nodal transport calculation agreed with the VIM Monte Carlo solution within $0.12 \% \Delta \mathrm{k}$. It was however observed that the calculated values consistently underestimated the criticality by $0.32 \% \Delta \mathrm{k}$ to $0.43 \% \Delta \mathrm{k}$.

The sodium void worths determined from VIM Monte Carlo and DIF3D nodal transport calculations were also very close to each other, but both predictions overestimated the measured void worth by $\sim 0.1 \% \Delta \mathrm{k}$, which amounted to $\sim 40 \%$ of the measured value. Further investigation is needed to identify the reason for this discrepancy between calculated and measured sodium void worths.

In summary, for all nine core configurations of ZPPR-21 and ZPPR-15 analyzed in this study, the deterministic transport solutions showed good agreement with Monte Carlo results. These results indicate that the existing deterministic methods for multigroup cross section generation and core calculation are adequate to use in the initial design stage of Advanced Burner Reactors, for which the startup fuel is expected to be conventional plutonium fuel. However, further verification/validation studies need to be performed for transmutation fuel to assess the impact of relatively large amount of minor actinides. In addition, to take into account the multi-dimensional heterogeneity effects properly, the current homogenization scheme based on one-dimensional cell calculation needs to be improved. 


\section{References}

1. W. S. Yang, et. al., "Preliminary Validation Studies of Existing Neutronics Analysis Tools for Advanced Burner Reactor Design Applications," ANL-AFCI-186, Argonne National Laboratory, April 2007.

2. L. G. Lesage, "An Overview of the Argonne National Laboratory Fast Critical Experiments 1963-1990,” ANL-NT-175, Argonne National Laboratory, April 2001.

3. H. F. McFarlane, S. B. Brumbach, S. G. Carpenter, and P. J. Collins, "Benchmark Physics Tests in the Metallic-Fueled Assembly ZPPR-15," Nucl. Sci. Eng., 101, 137-152 (1989).

4. R. N. Blomquist, "VIM Continuous Energy Monte Carlo Transport Code," Proc. Intl. Conf. on Mathematics, Computations, Reactor Physics and Environmental Analysis, Portland, OR, April 30-May 4, 1995.

5. R. M. Lell, R. W. Schaefer, R. D. McKnight, and A. Mohamed, "ZPPR-21 Phase A: A Cylindrical Assembly of $\mathrm{Pu}$ Metal Reflected by Graphite," PU-MET-FAST-033, OECD/NEA, International Handbook of Evaluated Criticality Safety Benchmark Experiments, NEA/NSC/DOC(95)03 (2005).

6. R. D. McKnight, R. M. Lell, R. W. Schaefer, and A. Mohamed, "ZPPR-21 Phases B through E: Cylindrical Assemblies of Mixed Fissile $\mathrm{Pu}$ and $\mathrm{U}$ Metal Reflected by Graphite," MIX-MET-FAST-011, OECD/NEA, International Handbook of Evaluated Criticality Safety Benchmark Experiments, NEA/NSC/DOC(95)03 (2005).

7. R. W. Schaefer, R. D. McKnight, R. M. Lell, and A. Mohamed, "ZPPR-21 Phase F: A Cylindrical Assembly of U Metal Reflected by Graphite," HEU-MET-FAST-061, OECD/NEA, International Handbook of Evaluated Criticality Safety Benchmark Experiments, NEA/NSC/DOC(95)03 (2005).

8. B. J. Toppel, H. Henryson II, and C. G. Stenberg, "ETOE-2/MC ${ }^{2}-2 / S D X$ Multigroup Cross-Section Processing," Conf-780334-5, Proc. of RSIC Seminar Workshop on Multigroup Cross Sections, Oak Ridge, TN (March 1978)

9. H. Henryson II, B. J. Toppel, and C. G. Stenberg, "MC'-2: A Code to Calculate Fast Neutron Spectra and Multigroup Cross Sections," ANL-8144, Argonne National Laboratory (1976).

10. Alcouffe, R. E., Brinkley, F. W., Marr, D. R., and O’Dell, R. D., “User's Guide for TWODANT: A Code Package for Two-Dimensional, Diffusion-Accelerated, NeutralParticle Transport," LA-10049-M, Los Alamos National Laboratory (1990).

11. R. N. Hwang, B. J. Toppel, and H. Henryson II, "Improved Algorithms for the Calculation of Resolved Resonance Cross Sections with Application to the Structural Doppler Effect," ANL-80-104, Argonne National Laboratory, October 1980.

12. R. N. Hwang, Private Communication, Argonne National Laboratory. August 2002.

13. Derstine, K. L., "DIF3D: A Code to Solve One-, Two-, and Three-Dimensional Diffusion Theory Problems," ANL-82-64, Argonne National Laboratory, (1982). 
14. R. D. Lawrence, "Progress in Nodal Methods for the Solution of the Neutron Diffusion and Transport Equations," Prog. Nucl. Energy, 17, 271 (1986).

15. P. J. Collins and S. B. Brumbach, Private Communication, Argonne National Laboratory, October 1985.

16. P. J. Collins and S. B. Brumbach, Private Communication, Argonne National Laboratory, April 1986.

17. R. D. Lawrence, "The DIF3D Nodal Neutronics Option for Two- and Three-Dimensional Diffusion Theory Calculations in Hexagonal Geometry," ANL-83-1, Argonne National Laboratory (1983). 